Article

\title{
Investigation of the Selectivity of L-Type Voltage-Gated Calcium Channels 1.3 for Pyrimidine-2,4,6-Triones Derivatives Based on Molecular Dynamics Simulation
}

\author{
Qi Ye®, Zhenyu Zhang, Wenying Zhang, Yushan Ding, Fan Zhao, Jinghai Zhang \\ and Yongbo Song *
}

School of Life Science and Biopharmaceutics, Shenyang Pharmaceutical University, 103 Wenhua Road, Shenyang 110016, China; yeokqi@163.com (Q.Y.); zzy18306510590@163.com (Z.Z.); wy2549925684@foxmail.com (W.Z.); dinng814@163.com (Y.D.); syphurabbit@163.com (F.Z.); zhangjinghai@syphu.edu.cn (J.Z.)

* Correspondence: songyongbo@syphu.edu.cn; Tel.: +86-024-43520923

Received: 24 October 2020; Accepted: 16 November 2020; Published: 20 November 2020

\begin{abstract}
Human $\mathrm{Ca}_{\mathrm{v}} 1.3\left(\mathrm{hCa}_{\mathrm{v}} 1.3\right)$ is of great interest as a potential target for Parkinson's disease. However, common medications like dihydropyridines (DHPs), a kind of classic calcium channel blocker, have poor selectivity to $\mathrm{hCa}_{\mathrm{v}} 1.3$ in clinical treatment, mainly due to being implicated in cardiovascular side-effects mediated by human $\mathrm{Ca}_{\mathrm{v}} 1.2\left(\mathrm{hCa}_{\mathrm{v}} 1.2\right)$. Recently, pyrimidine-2,4,6-triones (PYTs) have received extensive attention as prominent selective inhibitors to $\mathrm{hCa}_{\mathrm{v}} 1.3$. In this study, we describe the selectivity mechanism of PYTs for $\mathrm{hCa}_{\mathrm{v}} 1.2$ and $\mathrm{hCa}_{\mathrm{v}} 1.3$ based on molecular dynamic simulation methods. Our results reveal that the van der Waals (vdW) interaction was the most important force affecting selectivity. Moreover, the hydrophobic interaction was more conducive to the combination. The highly hydrophobic amino acid residues on $\mathrm{hCa}_{\mathrm{v}} 1.3$, such as V162 (IR1), L303 (IR2), M481 (IR3), and F484 (IR3), provided the greatest contributions in the binding free energy. On the other hand, the substituents of a halogen-substituted aromatic ring, cycloalkyl and norbornyl on PYTs, which are pertinent to the steric hindrance of the compounds, played core roles in the selectivity and affinity for $\mathrm{hCa}_{\mathrm{v}} 1.3$, whereas strong polar substituents needed to be avoided. The findings could provide valuable information for designing more effective and safe medicines for Parkinson's disease.
\end{abstract}

Keywords: $\mathrm{hCa}_{\mathrm{v}} 1.2 ; \mathrm{hCa}_{\mathrm{v}} 1.3$; selective inhibitor; pyrimidine-2,4,6-triones; molecular dynamics simulation

\section{Introduction}

Voltage-gated calcium channels (VGCCs) are important sensors that can convert changes in cell surface membrane potential into intracellular physiological activity changes [1]. Allowed to go through the central pore region to enter or release to the sides of the cell membrane, calcium ions could regulate intracellular calcium ion concentration [2]. Calcium ions in the cell act as second messengers for activating a range of physiological activities such as muscle contraction, neurotransmitter release, hormone secretion and gene expression [3]. According to electrophysiological standards, VGCC can be divided into high voltage-activation (HVA) types and low voltage-activation (LVA) types. The HVA is consisted of the L-type ( $\mathrm{Ca}_{\mathrm{v}} 1$ family), R-, P-/Q-, and N-type ( $\mathrm{Ca}_{\mathrm{v}} 2$ family), while the LVA is only composed of the T-type ( $\mathrm{Ca}_{\mathrm{v}} 3$ family) [4,5]. The members of the $\mathrm{Ca}_{\mathrm{v}} 1$ subfamily are classified into four isoforms $\left(\mathrm{Ca}_{\mathrm{v}} 1.1\right.$ to $\left.\mathrm{Ca}_{\mathrm{v}} 1.4\right)$ according to their different structures and expression distributions in physiological functions [5,6]. L-type voltage-gated calcium channels (LTCCs) are heteropolymers 
consisting of $\alpha 1, \alpha 2, \beta, \gamma$ and $\delta$ subunits [7]. $\alpha 1$ is crucial and can determine most of the biophysical and pharmacological properties of LTCCs. This subunit consists of four highly homologous transmembrane domains (DI-IV). Each domain contains six transmembrane spirals (S1-S6). Among them, S1-S4 form the voltage sensor domains (VSD), and S5-S6 with the extracellular regions (P-loops) constitute the central pore region of the channel [7,8]. Expressed in heart, smooth muscle, pancreas and brain, $\mathrm{Ca}_{\mathrm{v}} 1.2$ is the major and most widespread isoform (about 90\%) in the LTCCs. However, Ca 1.3 mainly remains in the neuron system $[9,10]$. This specificity of tissue distribution has led to many diseases closely related to LTCCs $[11,12]$. For example, human $\mathrm{Ca}_{\mathrm{v}} 1.2\left(\mathrm{hCa}_{\mathrm{v}} 1.2\right)$ is one of the important targets of cardiovascular diseases, whereas human $\mathrm{Ca}_{\mathrm{v}} 1.3\left(\mathrm{hCa}_{\mathrm{v}} 1.3\right)$ is involved in the pathogenesis of Parkinson's disease (PD) and is considered to be a therapeutic target for neurodegenerative diseases [13-17].

Several research reports have indicated some promising results for the traditional LTCCs' antagonists, such as the dihydropyridines (DHPs), benzothiazepines (BTZs) and phenylalkylamine (PAAs). Particular interest to the class of DHPs made them widely used in clinical treatment so that LTCCs are also termed as dihydropyridines receptors [18-24]. Due to the lack of selectivity of available pharmacological agents for $\mathrm{hCa}_{\mathrm{v}} 1.2$ and $\mathrm{hCa}_{\mathrm{v}} 1.3$, present medicines like DHPs for the treatment of neurodegenerative diseases are likely to cause potential cardiovascular side-effects mediated by $\mathrm{hCa}_{\mathrm{v}} 1.2$ [2]. Koscha et al. indicated that isradipine had a similar affinity to $\mathrm{hCa}_{\mathrm{v}} 1.2$ and $\mathrm{hCa} \mathrm{v}_{\mathrm{v}} 1.3$, but its inhibition rate of $\mathrm{hCa}_{\mathrm{v}} 1.2$ was about 10 -fold higher than that of $\mathrm{hCa} 1.3$ due to the difference in voltage dependence [25].

Among these studied compounds, none indicated high selectivity for $\mathrm{hCa}$ 1.3 $[10,25-28]$ except some pyrimidine-2,4,6-triones (PYTs) reported recently by Kang et al. In their research, the PYTs' scaffold was identified as the first class of selective antagonists for $\mathrm{hCa}_{\mathrm{v}}$ 1.3. Especially, the compound (1-(3-chlorophenethyl)-3-cyclopentylpyrimidine-2,4,6-trione) exhibited much higher $\mathrm{IC}_{50}$ of $\mathrm{hCa}_{\mathrm{v}} 1.3$ $(1.7 \mu \mathrm{M})$ in contrast to $\mathrm{hCa}_{\mathrm{v}} 1.2(1162 \mu \mathrm{M})$ [29]. Furthermore, many other PYTs have also been tested for their selectivity to $\mathrm{hCa}_{\mathrm{v}} 1.3$ and $\mathrm{hCa}_{\mathrm{v}} 1.2$ and the results are similar to this compound [30]. It can be seen that PYTs could be a potential selective antagonist for $\mathrm{hCa}_{\mathrm{v}} 1.3$. In addition, the active pocket that binding to benzodiazepines on LTCC is also reported as the binding site to PYTs [31]. These provide experimental support for elucidating the selective mechanism of these compounds to $\mathrm{hCa}_{\mathrm{v}} 1.2$ and $\mathrm{hCa}_{\mathrm{v}}$ 1.3. However, limited by the complex structures of LTCCs, exploring the interactions mentioned above relying on experimental methods consumes a lot of resources. Bioinformatics, which has been widely recognized and applied, becomes the best choice to solve this issue. In 2014, publication of the crystal structure of the calcium channel from the gram-negative pathogen Arcobacter butzleri $\left(\mathrm{Ca} \mathrm{V}_{\mathrm{v}} \mathrm{Ab}\right)$ paved the way for an in-depth understanding of LTCCs [32]. Recently, the structure solution of rabbit $\mathrm{Ca}_{\mathrm{v}} 1.1\left(\mathrm{rCa}_{\mathrm{v}} 1.1\right)$ through cryoelectron microscopy strengthened the foundation of research on calcium channel structure and function [33].

In this study, computational simulation methods were applied to investigate the differences in the selectivity of PYTs to $\mathrm{hCa}_{\mathrm{v}} 1.2$ and $\mathrm{hCa}_{\mathrm{v}} 1.3$. Based on the crystal structure of $\mathrm{rCa}_{\mathrm{v}} 1.1$, the pore domains of $h \mathrm{ha}_{\mathrm{v}} 1.2$ and $\mathrm{hCa}_{\mathrm{v}} 1.3$ were built by computer dynamics simulation. Two groups of PYTs (group A: PYT06, PYT22, PYT65; group B: PYT67, PYT103, PYT108; Figure 1 and Table S1 in Supplementary Material) were selected from previous studies [30]. The three compounds in each group were selected with high, low and no inhibition rates to $\mathrm{hCa}_{\mathrm{v}} 1.3$ and $\mathrm{hCa}_{\mathrm{v}} 1.2$. The specific binding characteristics and related key factors are described in detail to clarify the mechanism of $\mathrm{hCa}_{\mathrm{v}} 1.3$ selectivity. Our study could provide theoretical support and ideas for future studies of selective inhibitors of PYTs as well as the selective inhibitors of LTCCs. 
<smiles>O=C1CC(=O)N(C2CCCC2)C(=O)N1CCc1cccc(Cl)c1</smiles><smiles>O=C(O)[C@H]1CC[C@@H](N2C(=O)CC(=O)N(CCc3cccc(Cl)c3)C2=O)C1</smiles><smiles>CC1(C)CCCC1N1C(=O)CC(=O)N(CCc2ccc(Cl)cc2)C1=O</smiles>
PYT22

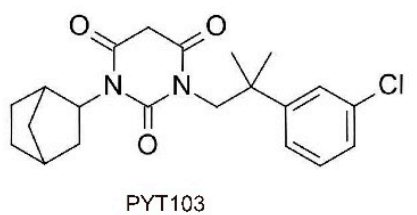<smiles>O=C1CC(=O)N(C2CCNC2)C(=O)N1CCc1cccc(Cl)c1</smiles>

PYT65<smiles>O=C1CC(=O)N(C2CC3CCC2C3)C(=O)N1CCc1cccc(C(F)(F)F)c1</smiles>

Figure 1. The chemical structure of selected pyrimidine-2,4,6-triones (PYTs) [30].

\section{Results}

\subsection{Analysis of 3D Structures of Pore Domains on $h C a_{v} 1.3$ and $h C a_{v} 1.2$}

The sequence identity of pore domains on $\mathrm{hCa}_{\mathrm{v}} 1.3 / \mathrm{Ca}_{\mathrm{v}} 1.2$ and $\mathrm{rCa}_{\mathrm{v}} 1.1$ was up to $70 \%$ (Figure S1 in Supplementary Material), which ensured the accuracy of these two models to a certain extent. As mentioned above, a total of 500 homology models were established, and the best models were selected based on the DOPE value and Molpdf score according to their energy [34]. The structures of hCav1.3/Cav1.2 (Figure S2 in supplementary material) were evaluated by ERRAT, PROCHECK, and WHATCHECK [35-38], and the results are shown in Supplementary Table S2. The average values of the overall quality factors of ERRAT are 70.75 and 73.89, respectively, showing a great quality for two structures. The Ramachandran plot in PROCHECK was used to analyze residue-by-residue geometry and overall structure geometry of the protein structure. The analysis results (Figure S3 in Supplementary Material) indicated that about $98.5 \%$ and $97.5 \%$ residues in $\mathrm{hCa}_{\mathrm{v}} 1.3$ and $\mathrm{hCa}_{\mathrm{v}} 1.2$, respectively, were in the most favored regions and additional allowed regions. Moreover, the residues in the disallowed regions were generally the terminal residues. The root-mean-square Z-scores (RMS Z-scores) of bond lengths and bond angle from the WHATCHECK also confirmed that the model had better stereochemical properties compared to other models. Additionally, 50 ns preliminary simulation was performed on the initial structure to verify stability. The structure alignment between the initial structure and simulated structure of $\mathrm{hCa}_{\mathrm{v}} 1.3$ and $\mathrm{hCa}_{\mathrm{v}} 1.2$ returned the root-mean-square-deviations (RMSD) of $2.3 \AA$ and $2.5 \AA$ (Figure 2), respectively. It was shown that $h \mathrm{Ca}_{\mathrm{v}} 1.2$ was more unstable than $h \mathrm{ha}_{\mathrm{v}} 1.3$ and the main fluctuant regions of $\mathrm{hCa}_{\mathrm{v}} 1.2$ were located in DI and DIII. Few displacements were detected in the transmembrane helices near the binding site for both. Subsequently, the homology models of hCa 1.3 and $\mathrm{hCa}_{\mathrm{v}} 1.2$ were prepared for membrane-embedded protein simulation with water as solvent (Figure S4 in Supplementary Material) for further studies.

\subsection{Molecular Dynamics Simulation of $h C a_{v} 1.3 / C a_{v} 1.2-P Y T s$ Complexes}

Molecular docking was used to generate the initial structures of molecular dynamics (MD) simulation, and the best complexes of $\mathrm{hCa}_{\mathrm{v}} 1.3 / \mathrm{hCa}_{\mathrm{v}} 1.2$ were selected based on the docking conformation and binding energy. MD simulations of $100 \mathrm{~ns}$ were carried out to the $\mathrm{hCa} \mathrm{a}_{\mathrm{v}} 1.3 / \mathrm{Ca}_{\mathrm{v}} 1.2-\mathrm{PYTs}$ complexes. The RMSD of $\mathrm{hCa}_{\mathrm{v}} 1.3$ and $\mathrm{hCa} \mathrm{a}_{\mathrm{v}} 1.2$ for PYTs in group A (PYT06, PYT22, and PYT65) are exhibited in Figure $3 a, b$. It was shown that the last 40 ns were relatively stable for all complex systems. However, the systems related to $h \mathrm{Ca}_{\mathrm{v}} 1.2$ obviously had a larger average RMSD value $(4.02 \AA)$ compared with the systems related to $\mathrm{hCa}_{\mathrm{v}} 1.3$ (2.94 $\AA$ ), especially the complex of $\mathrm{hCa}_{\mathrm{v}} 1.2-\mathrm{PYT06}$ (red curve in Figure 3b) whose average RMSD value was $4.48 \AA$ in the final $40 \mathrm{~ns}$, exhibiting a greater range of fluctuation than the other complexes. In consideration of the same template used for constructing the models of $\mathrm{hCa}_{\mathrm{v}} 1.2$ and $\mathrm{hCa}_{\mathrm{v}} 1.3$, it is reasonable to believe that these differences were generated by different affinities of binding ligands. 

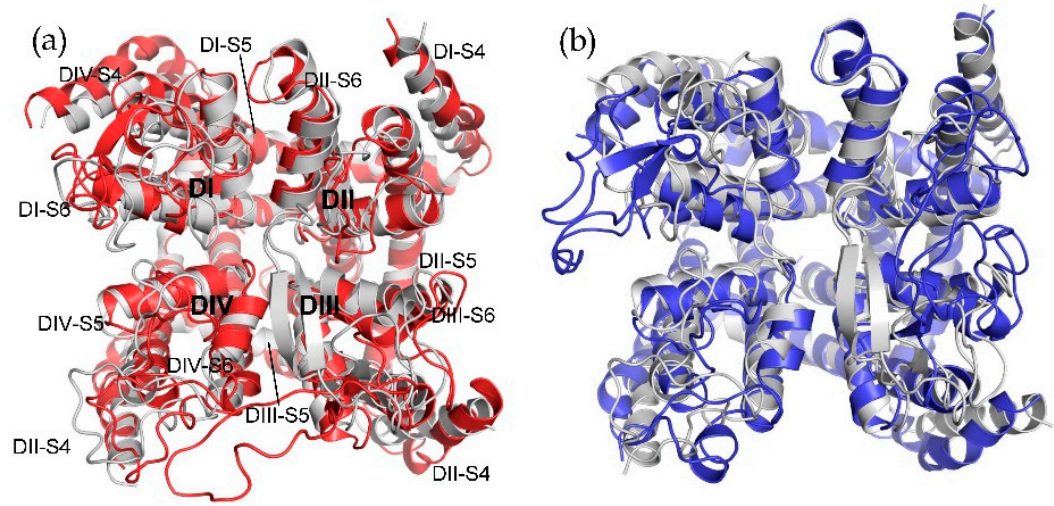

Figure 2. The structure alignment between the initial structure (gray) and simulated structure (red and blue) for $\mathrm{hCa}_{\mathrm{v}} 1.3$ (a) and $\mathrm{hCa}_{\mathrm{v}} 1.2(\mathbf{b})$. The domain was marked in hCav1.3 based on the names.

(a)

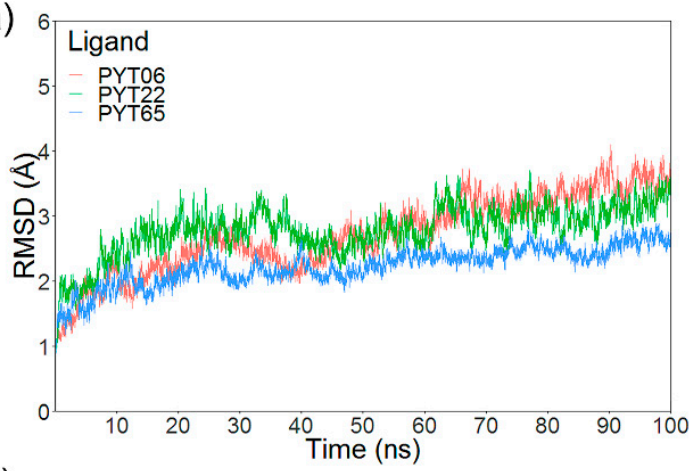

(c)

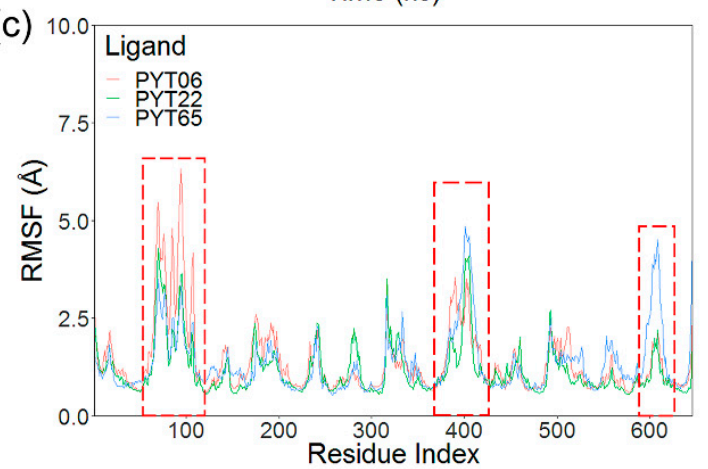

(b)

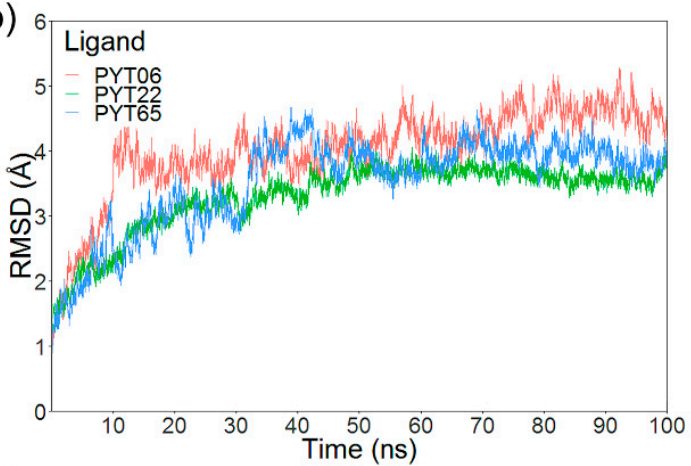

(d) 100

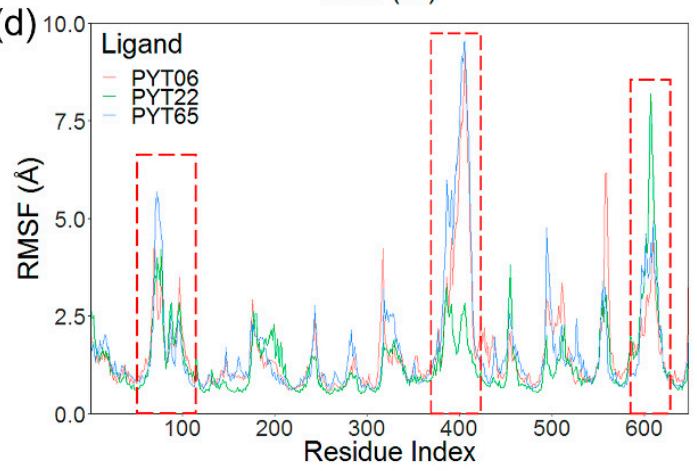

Figure 3. RMSD curves of the systems of $h \mathrm{ha}_{\mathrm{v}} 1.3(\mathbf{a})$ and $\mathrm{hCa}_{\mathrm{v}} 1.2(\mathbf{b})$ with PYT06 (pink), PYT22 (green), and PYT65 (blue). RMSF curves by residues in $\mathrm{hCa}_{\mathrm{v}} 1.3$ (c) and $\mathrm{hCa}_{\mathrm{v}} 1.2$ (d) systems. The main fluctuating regions were enclosed in red dashed rectangles.

As shown in Figure 3c,d, the root-mean-square fluctuation (RMSF) curves indicated that three main fluctuating regions (marked with red dashed rectangles in Figure 3) in these two LTCCs were found. These regions were mainly located in the extracellular loops between S5 and S6. Except for flexible regions in the terminals of the receptors, most of the residues showed few movements in the three complexes of $\mathrm{hCa}_{\mathrm{v}} 1.2$. Besides, it was noticed that the second fluctuating region (383th-416th residues) in the complexes of $\mathrm{hCa}_{\mathrm{v}} 1.2-\mathrm{PYT} 06$ and $\mathrm{hCa} \mathrm{a}_{\mathrm{v}} 1.2-\mathrm{PYT} 65$ exhibited stronger fluctuations than the others.

Each $h \mathrm{ha}_{\mathrm{v}} 1.3$ and $\mathrm{hCa} \mathrm{a}_{\mathrm{v}} 1.2$ complex system eventually became steady during the whole simulation. However, the fluctuation of $\mathrm{hCa}_{\mathrm{v}} 1.2$ complex systems was greater than that of the $\mathrm{hCa}_{\mathrm{v}} 1.3$ complex systems, which was particularly obvious in $\mathrm{hCa}_{\mathrm{v}} 1.2-\mathrm{PYT} 06 / \mathrm{PYT} 65$ complexes. According to the experimental data [29], the PYT06 and PYT65 had low inhibition on $\mathrm{hCa}_{\mathrm{v}}$ 1.2. Therefore, it seemed that the low inhibition of the ligand could result in structural instability for $\mathrm{hCa}_{\mathrm{v}} 1.2$, but no such situation 
was found in $\mathrm{hCa}_{\mathrm{v}} 1.3$ complex systems. Thus, $\mathrm{hCa}_{\mathrm{v}} 1.2$ seemed to be more sensitive to the binding strength of the ligand.

\subsection{Analysis of Binding Modes of Complex Systems}

The molecular mechanics/generalized Born surface area (MM/GBSA) method was carried out in the last 20 ns of MD trajectories. As can be seen in Table 1, the total free binding energy of each complex was calculated and the results were generally consistent with the selectivity of experimental data. Compared to $\mathrm{hCa}_{\mathrm{v}} 1.2$, PYT06 had a high selectivity to $\mathrm{hCa}$ 1.3, PYT22 had strong binding affinities for both, whereas PYT65 was weak in combination with both. Moreover, the van der Waals interaction energy $\left(\Delta \mathrm{E}_{\mathrm{vdW}}\right)$ was confirmed as the primary influence factor of the binding free energy in the binding of PYTs with $\mathrm{hCa}_{\mathrm{v}} 1.2$ and $\mathrm{hCa}_{\mathrm{v}} 1.3$.

Table 1. Binding free energy between hCav1.3/Cav1.2 and PYTs of group A.

\begin{tabular}{|c|c|c|c|c|c|}
\hline Complexes & $\Delta \mathrm{E}_{\mathrm{vdW}}$ & $\Delta \mathrm{E}_{\mathrm{EL}}$ & $\Delta \mathrm{E}_{\mathrm{GB}}$ & $\Delta \mathrm{E}_{\text {SURF }}$ & $\Delta \mathrm{E}_{\text {total }}$ \\
\hline hCa $1.3-P Y T 06$ & -43.11 & -3.85 & 18.06 & -5.05 & -33.95 \\
\hline $\mathrm{hCa}_{\mathrm{V}} 1.2-\mathrm{PYT} 06$ & -28.73 & -4.55 & 18.20 & -3.68 & -18.77 \\
\hline $\mathrm{hCa}_{\mathrm{V}} 1.3-\mathrm{PYT} 22$ & -44.44 & -4.56 & 18.95 & -5.14 & -35.19 \\
\hline $\mathrm{hCa}_{\mathrm{v}} 1.2-\mathrm{PYT} 22$ & -37.14 & -3.77 & 15.73 & -4.48 & -29.66 \\
\hline $\mathrm{hCa}_{\mathrm{V}} 1.3-\mathrm{PYT} 65$ & -36.04 & -5.34 & 19.27 & -4.44 & -26.56 \\
\hline $\mathrm{hCa}_{\mathrm{v}} 1.2-\mathrm{PYT} 65$ & -32.76 & -9.78 & 21.44 & -4.25 & -25.35 \\
\hline
\end{tabular}

All the energies are in $\mathrm{kcal} / \mathrm{mol} ; \Delta \mathrm{E}_{\mathrm{vdW}}$ : van der Waals interaction energy; $\Delta \mathrm{E}_{\mathrm{EL}}$ : electrostatic interaction energy; $\Delta \mathrm{E}_{\mathrm{GB}}$ : polar solvation energy contribution; $\Delta \mathrm{E}_{\mathrm{SURF}}$ : nonpolar solvation energy contribution; $\Delta \mathrm{E}_{\text {total: }}$ the total binding free energy by MM/GBSA.

Furthermore, 3D binding conformations and energy decomposition of per-residue were used to determine the critical residues and regions in the combinations of PYTs to $\mathrm{hCa}_{\mathrm{v}} 1.2$ and $\mathrm{hCa}$ 1.3. The major interactional regions (termed IR1-IR4) in four domains of each system are listed in Supplementary Table S3, where residues with high energy contributions are shown. As shown in Figure 4 , in the system of $\mathrm{hCa}_{\mathrm{v}}$ 1.3-PYT06, three major interaction regions (IR1-IR3) were obviously found in the binding pocket located in DI, DII, and DIII, respectively. Among them, IR2 had the highest energy contribution to the binding free energy, and the binding site in the center pore remained highly hydrophobic. The PYT06 formed Pi-Alkyl hydrophobic contacts with V162 and L165 on hCa 1.3 through chlorophenyl and interacted with N300, L304, and M481 as well. These important residues with other hydrophobic residues formed an intensive hydrophobic surface around the binding pocket. However, in comparison to active pockets on $\mathrm{hCa}_{\mathrm{v}} 1.2$ and $\mathrm{hCa}_{\mathrm{v}} 1.3$ when combined with PYT06, there was only residue $\mathrm{L} 305$ in the IR2 in $\mathrm{hCa}_{\mathrm{v}}$ 1.2. Moreover, the interactive regions showed a reduction of residue energy contribution (Figure $4 \mathrm{c}, \mathrm{d}$ ) for the $\mathrm{hCa}_{\mathrm{v}} 1.2-\mathrm{PYT06}$ complex, although it had similar interactive regions to the $\mathrm{hCa}_{\mathrm{v}}$ 1.3-PYT06 complex. The binding site of $\mathrm{hCa}_{\mathrm{v}} 1.2$ and PYT06 was closer to DIII and DIV, and this region had lower hydrophobicity. Therefore, compared with hCa 1.2, PYT06 had the strongest selectivity for $\mathrm{hCa}_{\mathrm{v}} 1.3$ because it had higher hydrophobic interaction.

As can be seen in Figure 5, for complexes of $\mathrm{hCa}_{\mathrm{v}} 1.2-\mathrm{PYT} 22$ and $\mathrm{hCa} \mathrm{v}_{\mathrm{v}} 1.3-\mathrm{PYT} 22$, the regions with great energy contributions could be divided into four parts (IR1-IR4), where the locations were all similar. Interestingly, most of the residues in these four regions were hydrophobic amino acids. The low binding free energy was both reflected in the complexes of $\mathrm{hCa}_{\mathrm{v}} 1.2-\mathrm{PYT} 22(-29.6581 \mathrm{kcal} / \mathrm{mol})$ and $\mathrm{hCa}_{\mathrm{v}} 1.3-\mathrm{PYT} 22(-35.1939 \mathrm{kcal} / \mathrm{mol})$. On the one hand, M481 and F484 of $\mathrm{hCa}_{\mathrm{v}} 1.3, \mathrm{M} 481$, and F485 of $\mathrm{hCa}_{\mathrm{v}} 1.2$ in IR3 contributed the most to the combination. On the other hand, the chlorophenyl on PYT22 formed the Pi-alkyl interactions and alkyl (-Cl) interactions with V162/I634 and L163/L637 on hCa 1.3 , respectively. For the $\mathrm{hCa}_{\mathrm{v}} 1.2$, there were also the Pi-alkyl interactions and alkyl (-Cl) interactions between the chlorophenyl on PYT22 and M481/I637 and Met481. The distinction of residues in IR1 between $\mathrm{hCa}_{\mathrm{v}} 1.3(\mathrm{~V} 162, \mathrm{~L} 163, \mathrm{~V} 166)$ and $\mathrm{hCa}_{\mathrm{v}} 1.2$ (V164) was the main reason that caused different affinity of PYT22 to both. The dimethyl on the cyclopentyl ring of PYT22 provided more potential 
for binding free energy. Thus, the binding free energy of the two complexes that bound PYT22 was relatively low, which was consistent with the experiment results.

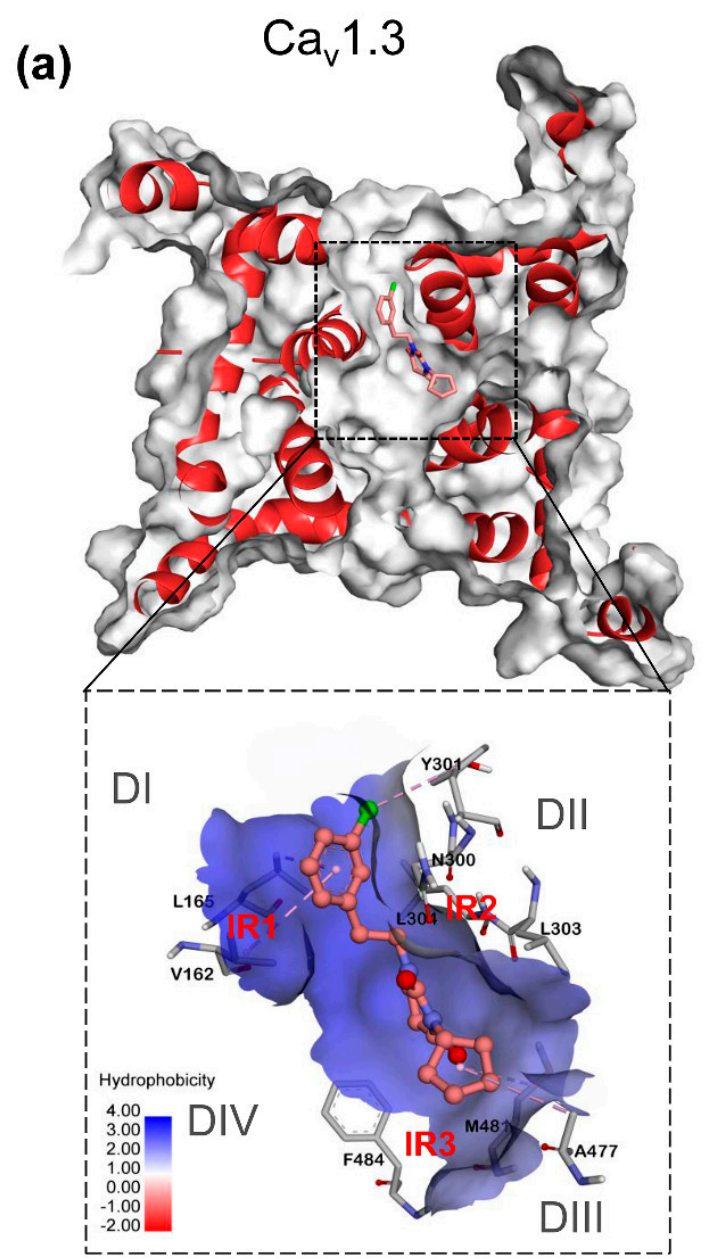

(c)

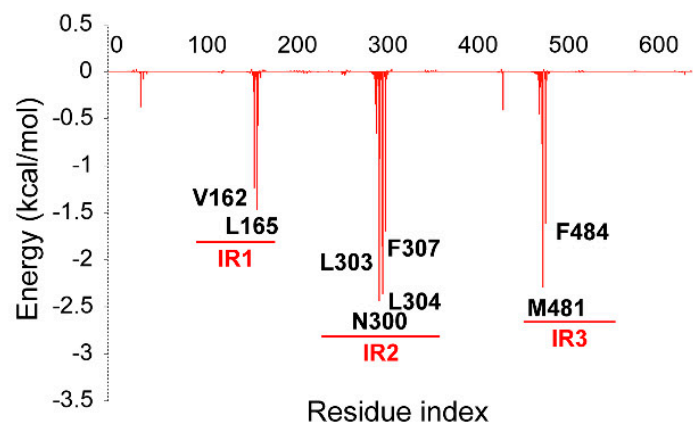

(b) $\quad \mathrm{Ca}_{\mathrm{v}} 1.2$

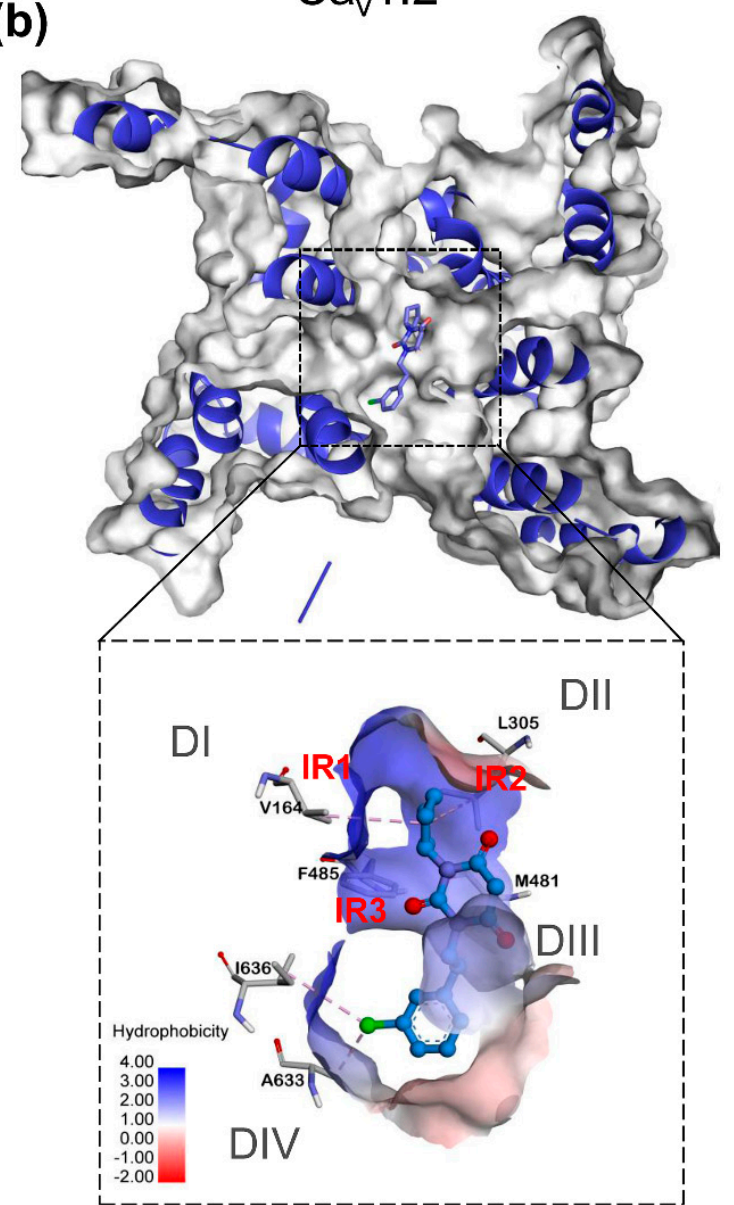

(d)

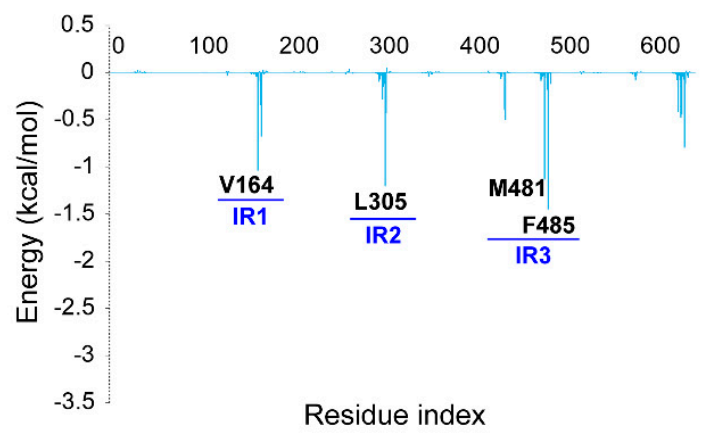

Figure 4. The binding conformation with the hydrophobic surface of the complexes of hCa $1.3-\mathrm{PYT06}$ (a) and $\mathrm{hCa}_{\mathrm{v}}$ 1.2-PYT06 (b). Deeper blue area on the surface indicates high hydrophobicity and vice versa. The energy decomposition of complexes of $\mathrm{hCa}_{\mathrm{v}} 1.3-\mathrm{PYT06}(\mathbf{c})$ and $\mathrm{hCa} \mathrm{v}_{\mathrm{v}} 1.2-\mathrm{PYT06}(\mathrm{d})$. The main interaction regions (IR) are marked in the figure. 


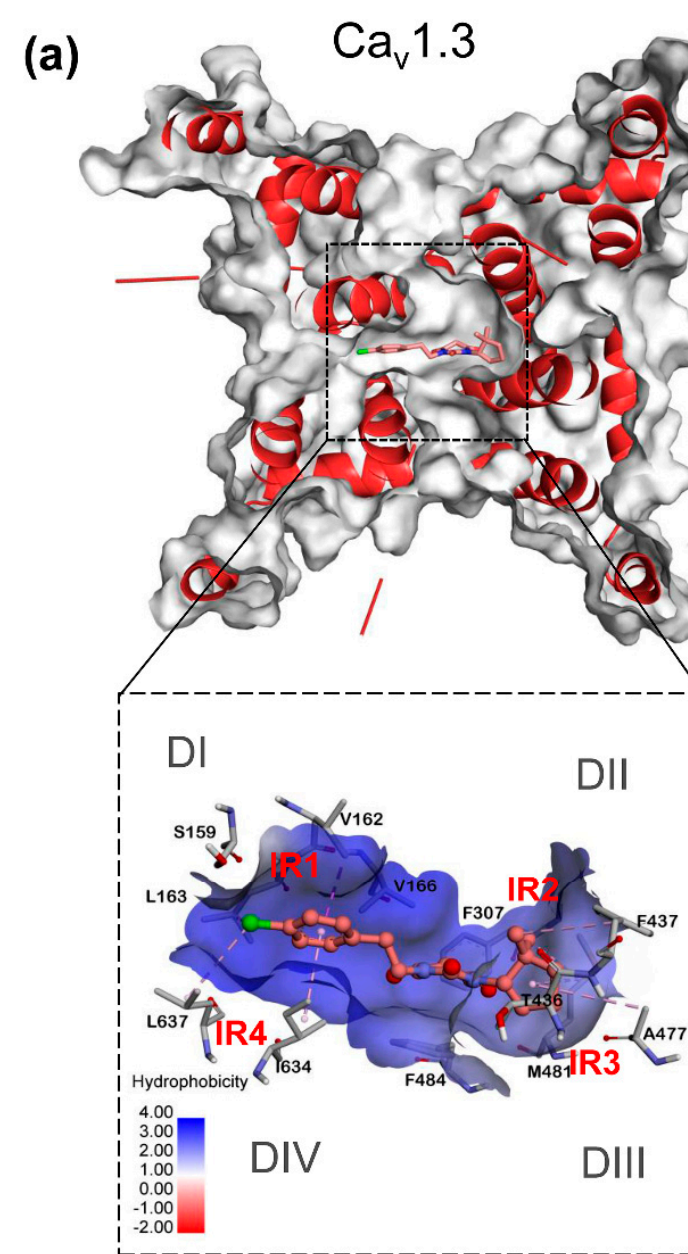

(c)

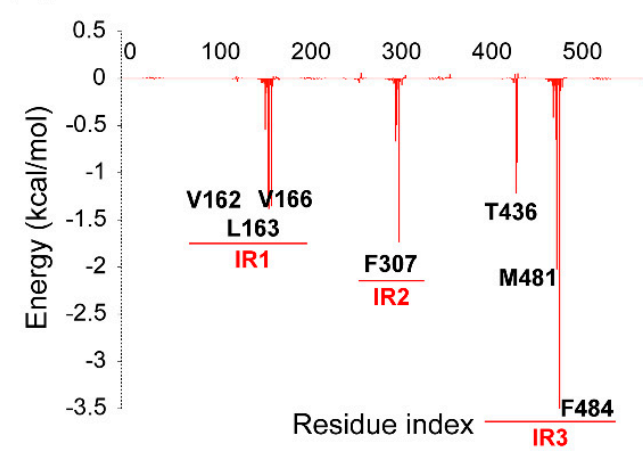

(b)

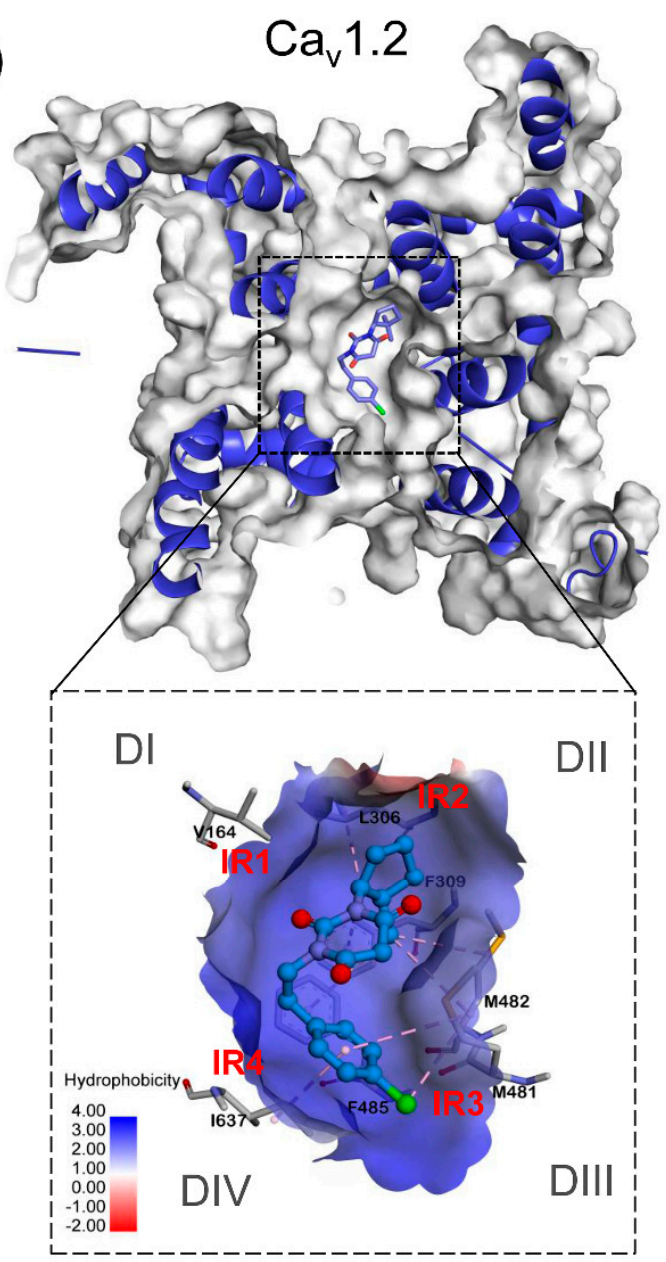

(d)

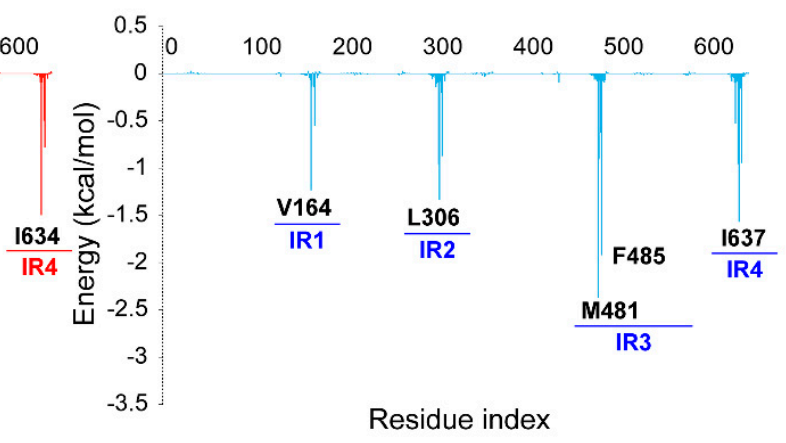

Figure 5. The binding conformation with the hydrophobic surface of the complexes of hCa $1.3-\mathrm{PYT} 22$ (a) and hCa $1.2-P Y T 22(b)$. Deeper blue area on the surface indicates high hydrophobicity and vice versa. The energy decomposition of complexes of hCa $\mathrm{h}_{\mathrm{v}} 1.3-\mathrm{PYT} 22(\mathrm{c})$ and $\mathrm{hCa}_{\mathrm{v}} 1.2-\mathrm{PYT} 22(\mathrm{~d})$. The main interaction regions (IR) are marked in the figure.

As shown in Figure 6, in contrast to PYT22, PYT65 displayed a large difference when combined with $\mathrm{hCa}_{\mathrm{v}} 1.2$ and $\mathrm{hCa}_{\mathrm{v}}$ 1.3. Because of the polar nitrogen of pyrrolidine, PYT65 bound to the less hydrophobic pocket that was closer to DIII and DIV on the receptors. This led to critical interaction residues concentrated on IR3 and IR4. Meanwhile, the binding site of PYT65 deviated from the center pore region, which caused reduction of hydrophobic interactions. The contributions made by the residues on DI and DII were significantly reduced, especially on $\mathrm{hCa}_{\mathrm{v}} 1.2$. It could be deduced that this 
was the main reason that caused the complexes with PYT65 to show higher binding free energy than the complexes of PYT22.

(a)

(c)

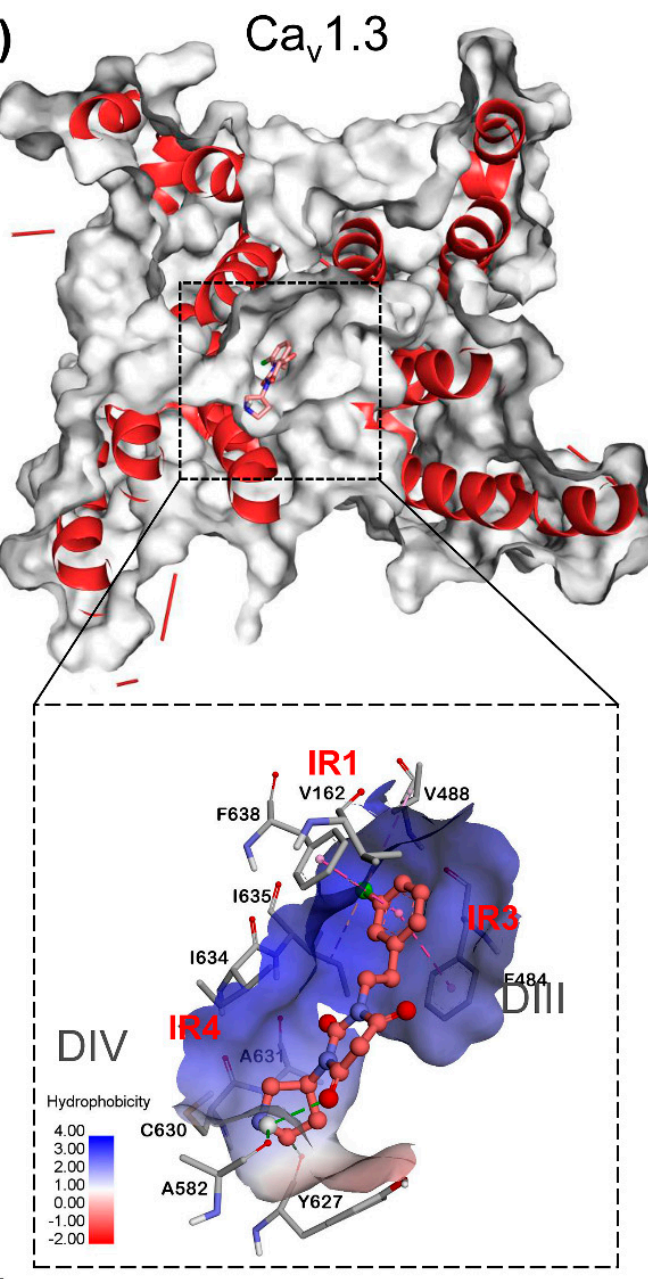$$
\text { (c) }
$$

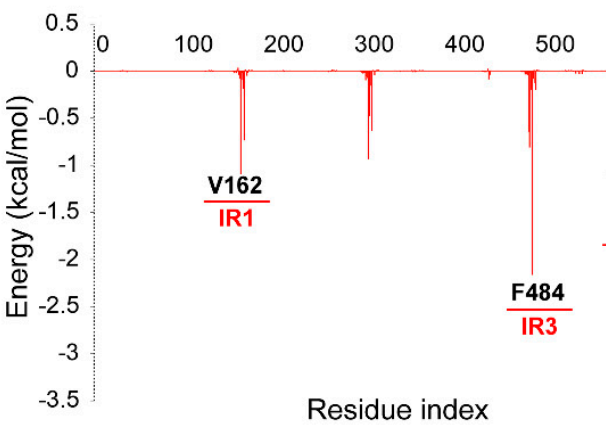

(b)

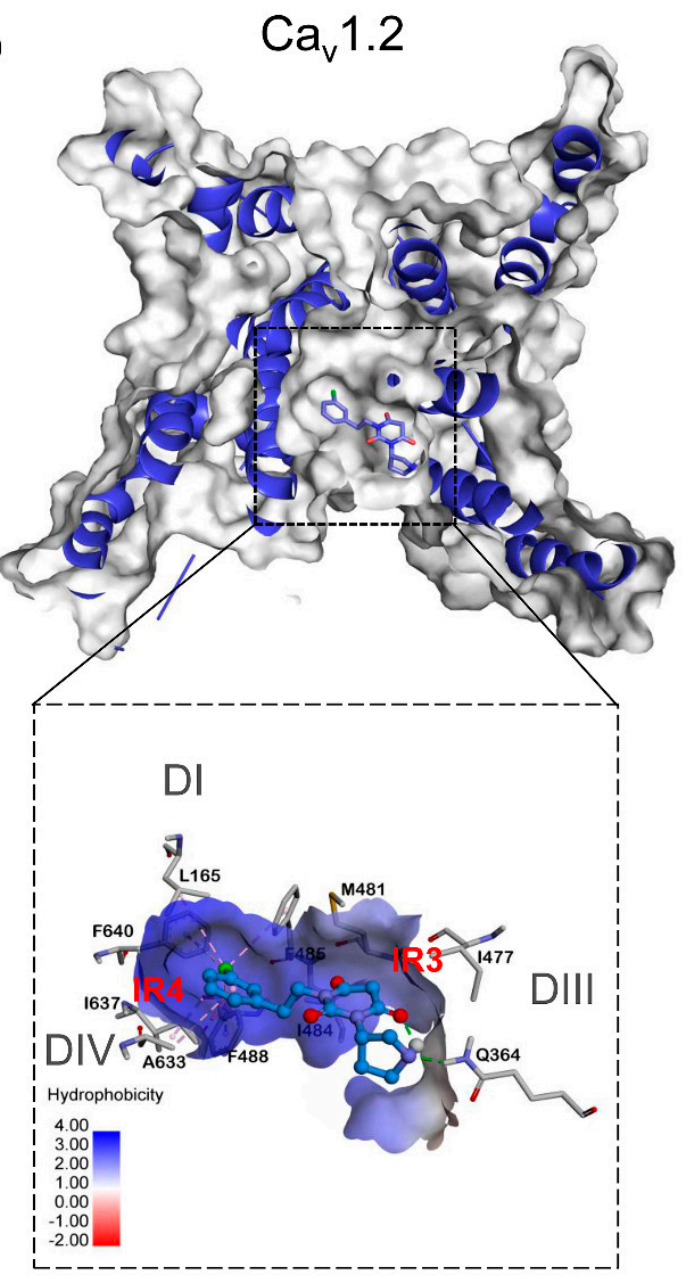

(d)

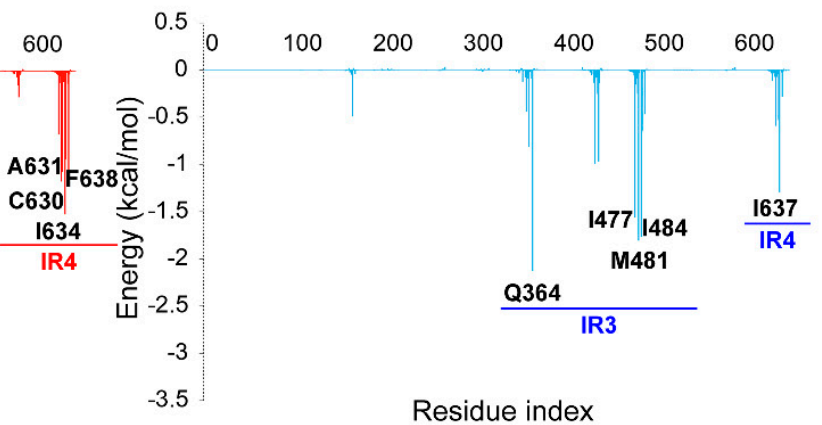

Figure 6. The binding conformation with the hydrophobic surface of the complexes of hCa $1.3-\mathrm{PYT} 65$ (a) and hCa $1.2-P Y T 65(b)$. Deeper blue area on surface indicates high hydrophobicity and vice versa. The energy decomposition of complexes of hCa $\mathrm{h}_{\mathrm{v}} 1.3-\mathrm{PYT} 65$ (c) and $\mathrm{hCa} \mathrm{a}_{\mathrm{v}} 1.2-\mathrm{PYT} 65$ (d). The main interaction regions (IR) are marked in the figure.

As a whole, it was not difficult to find that the highly hydrophobic surface made by residues in IR2 and IR3 was the major factor to influence the selectivity to $\mathrm{Ca}_{\mathrm{V}} 1.3$. The nonpolar substituent on the PYT ring could improve the interaction of PYTs with $h \mathrm{ha}_{\mathrm{v}} 1.3 / \mathrm{Ca}_{\mathrm{v}} 1.2$. 


\subsection{Verification of the Binding Mode}

The duplicate process was carried out with the same parameter for each system in group A, and the binding free energy and per-residue energy decomposition were calculated. The results of the binding free energy are listed in Table 2. Compared to $\mathrm{hCa}_{\mathrm{v}} 1.2$, it is not surprising that the PYT108 showed a higher affinity to $\mathrm{hCa}_{\mathrm{v}} 1.3$, which was consistent with experimental data. For the PYT103 with the high affinity to $\mathrm{hCa}_{\mathrm{v}} 1.2$ and $\mathrm{hCa}_{\mathrm{v}} 1.3$, both the $\mathrm{hCa}$ 1.2-PYT103 and hCa $1.3-\mathrm{PYT} 103 \mathrm{had}$ low binding free energy, and the $\mathrm{hCa}_{\mathrm{v}} 1.3-\mathrm{PYT} 67$ and $\mathrm{hCa}_{\mathrm{v}} 1.2-\mathrm{PYT} 67$ showed much higher values of binding free energy.

Table 2. Binding free energy between hCav1.3/Cav1.2 and PYTs of group B.

\begin{tabular}{cccccc}
\hline Complexes & $\Delta \mathrm{E}_{\mathbf{v d W}}$ & $\Delta \mathrm{E}_{\mathrm{EL}}$ & $\Delta \mathrm{E}_{\mathrm{GB}}$ & $\Delta \mathrm{E}_{\mathbf{S U R F}}$ & $\Delta \mathrm{E}_{\text {total }}$ \\
\hline $\mathrm{hCa} \mathrm{v}_{\mathrm{v}} 1.3-P Y T 108$ & -38.49 & -4.64 & 16.21 & -5.09 & -32.01 \\
$\mathrm{hCa} 1.2-P Y T 108$ & -34.87 & -2.84 & 18.25 & -4.37 & -23.84 \\
$\mathrm{hCa} 1.3-P Y T 103$ & -42.42 & -15.25 & 26.89 & -5.11 & -35.90 \\
$\mathrm{hCa}_{\mathrm{v}} 1.2-P Y T 103$ & -38.34 & -2.00 & 13.78 & -4.23 & -30.78 \\
$\mathrm{hCa}_{\mathrm{v}} 1.3-P Y T 67$ & -32.77 & -10.40 & 24.22 & -4.07 & -23.02 \\
$\mathrm{hCa}_{\mathrm{v}} 1.2-\mathrm{PYT} 67$ & -35.24 & -5.16 & 18.60 & -4.18 & -25.99 \\
\hline
\end{tabular}

All the energies are in $\mathrm{kcal} / \mathrm{mol} ; \Delta \mathrm{E}_{\mathrm{vdW}}$ : van der Waals interaction energy; $\Delta \mathrm{E}_{\mathrm{EL}}$ : electrostatic interaction energy; $\Delta \mathrm{E}_{\mathrm{GB}}$ : polar solvation energy contribution; $\Delta \mathrm{E}_{\mathrm{SURF}}$ : nonpolar solvation energy contribution; $\Delta \mathrm{E}_{\text {total }}$ : the total binding free energy by MM/GBSA.

In order to further confirm the key factors that affect the selectivity difference of PYTs on the $\mathrm{hCa}_{\mathrm{v}} 1.3 / \mathrm{Ca}_{\mathrm{v}} 1.2$, other PYTs (group B) were selected to verify the results obtained by group A again. As displayed in Figures 7 and 8, the energy decomposition of residues and the structures with the hydrophobic surface provided valuable information for the selectivity of $h \mathrm{ha}_{\mathrm{v}} 1.3 / \mathrm{Ca}_{\mathrm{v}} 1.2$. The residues in each of the main interactive regions of $\mathrm{hCa}_{\mathrm{v}} 1.3$ and $\mathrm{hCa}_{\mathrm{v}} 1.2$ complexes are listed in Supplementary Table S4. In the $\mathrm{hCa}_{\mathrm{v}} 1.3-\mathrm{PYT} 108$, the residues in IR2 and IR3 were found to be the main interactive regions to retain the high binding free energy. The residues L303 in IR2, M480, and M481 in IR3 played an important role in the energy contribution of $\mathrm{hCa}_{\mathrm{v}} 1.3-\mathrm{PYT108}$. It was also confirmed in the $\mathrm{hCa}_{\mathrm{v}} 1.3-\mathrm{PYT06}$ system that these residues were more important to the selectivity of $\mathrm{hCa}_{\mathrm{v}} 1.3$. In contrast, the $\mathrm{hCa}_{\mathrm{v}} 1.2-\mathrm{PYT} 108$ could not retain the low binding free energy due to the lack of residues with high energy contribution in IR2 and IR3. 
(a)

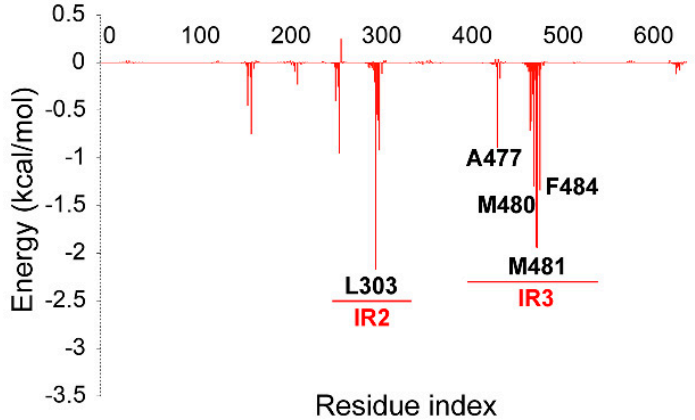

(c)

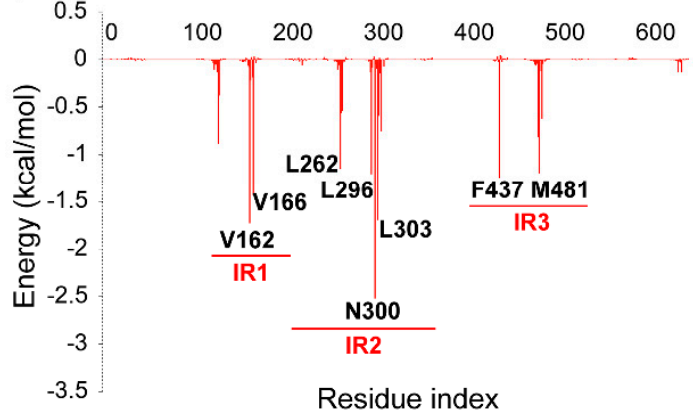

(e)

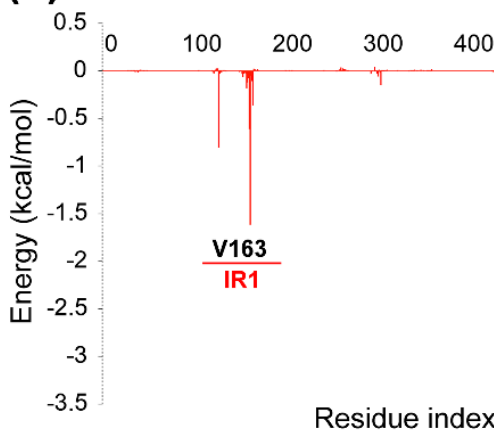

(b)

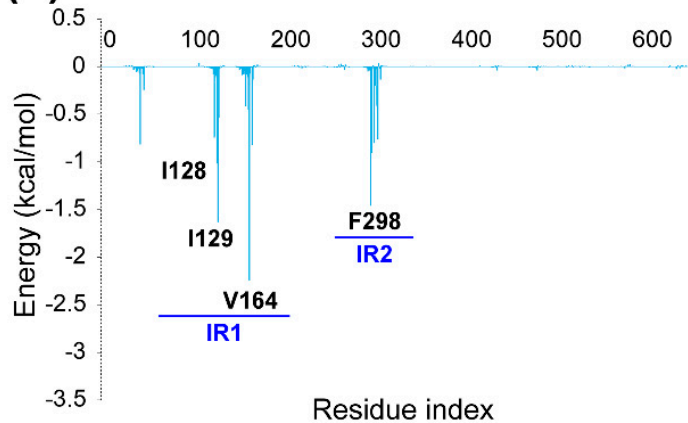

(d)

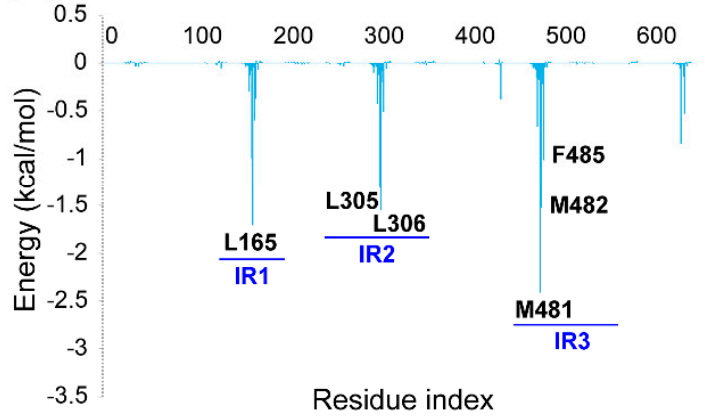

(f)

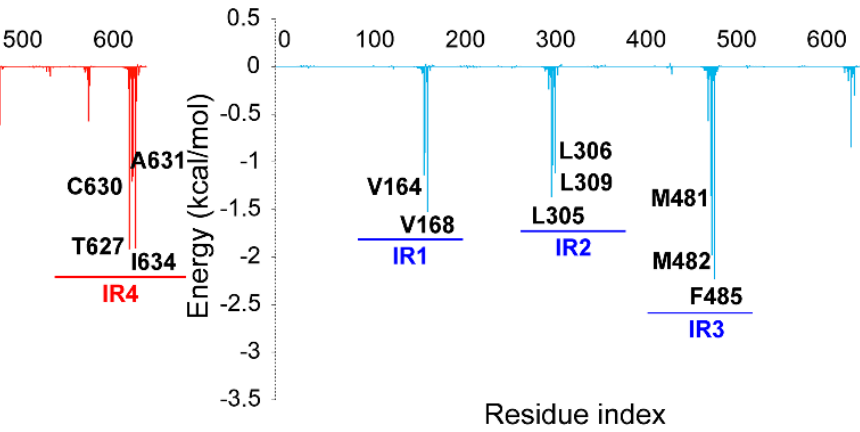

Figure 7. The per-residue energy decomposition of the complexes of PYT108 (a,b) and PYT103 (c,d) and PYT67 (e,f) for hCa $1.3(\mathbf{a}, \mathbf{c}, \mathbf{e})$ and $\mathrm{hCa}_{\mathrm{v}} 1.2(\mathbf{b}, \mathbf{d}, \mathbf{f})$. The main interaction regions (IR) are marked under the corresponding residues. 
(a)

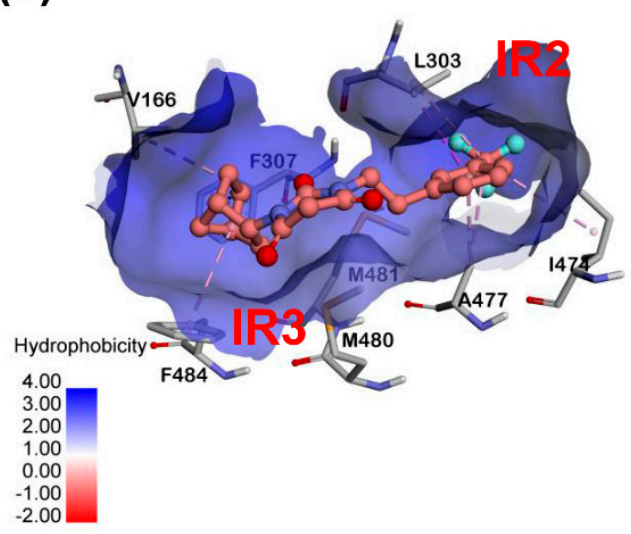

(c)

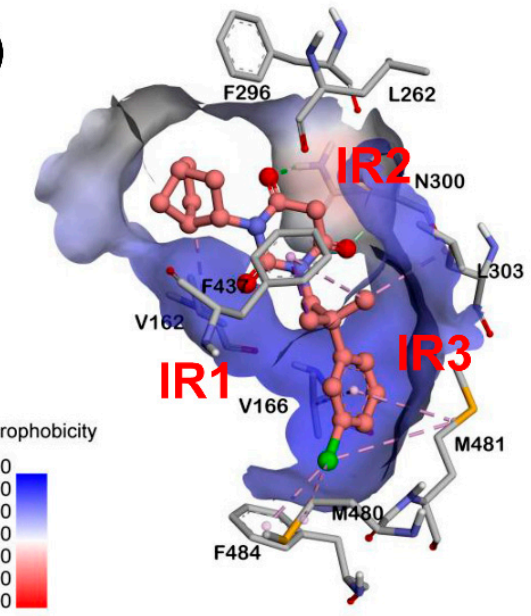

(e)

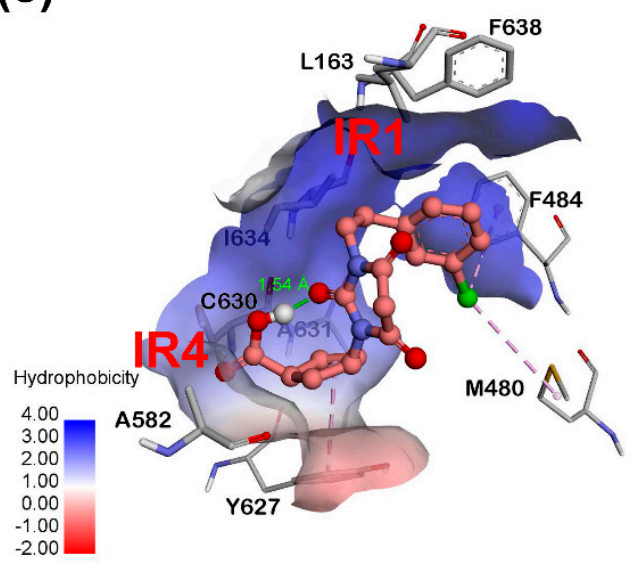

(b)

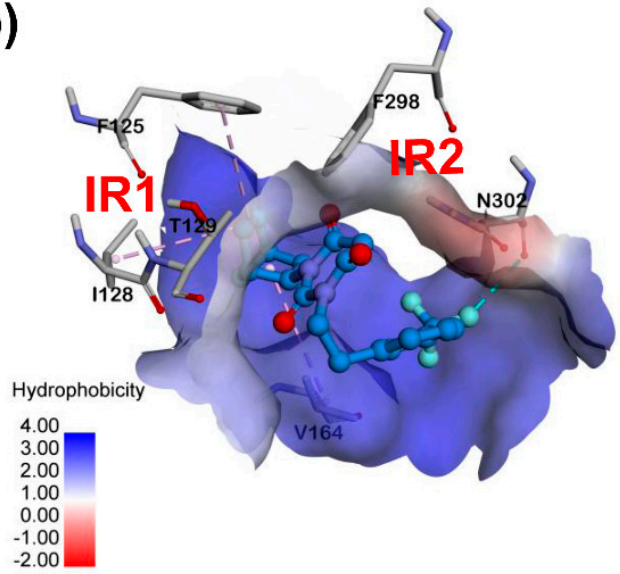

(d)

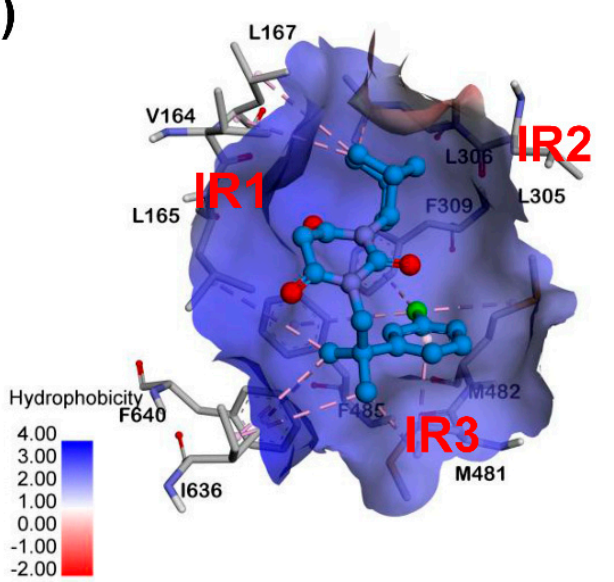

(f)

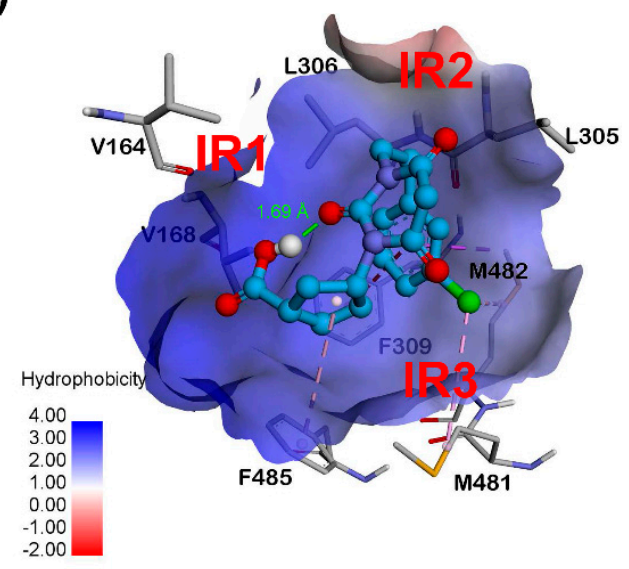

Figure 8. The binding mode with hydrophobic surface of complexes of PYT108 (a,b), PYT103 (c,d), and PYT67 (e,f) for hCa $1.3(\mathbf{a}, \mathbf{c}, \mathbf{e})$ and $\mathrm{hCa}_{\mathrm{v}} 1.2(\mathbf{b}, \mathbf{d}, \mathbf{f})$. The main interaction regions (IR) are marked in red.

\section{Discussion}

$h \mathrm{ha}_{\mathrm{v}} 1.2$ and $\mathrm{hCa}_{\mathrm{v}} 1.3$ are the main isoforms of LTCCs with the widest distribution and expression. However, due to their highly-homologous sequences, similar structures, and pharmacological properties, traditional calcium channel blockers (CCB) used in clinical treatment exhibited poor selectivity to these two subtypes. Based on the experimental data published, PYTs are a kind of 
potential selective inhibitor to $\mathrm{hCa}_{\mathrm{v}} 1.3[29,30]$. Therefore, it is necessary to elucidate the mechanism of selectivity of $\mathrm{hCa}_{\mathrm{v}} 1.3$ and $\mathrm{hCa} \mathrm{v}_{\mathrm{v}} 1.2$.

In this study, six PYTs were divided into two groups (A, B) according to different selectivity and structure. There were two substituents on the PYT ring. One of the substituents was a five-membered ring, such as cyclopentyl (PYT06), dimethylcyclopentyl (PYT22), or pyrrolidinyl (PYT65) in group A, and formyloxycyclopentyl (PYT69) or norbornyl (PYT103, PYT108) in group B. The other one was a halogen-substituted aromatic ring, including trifluoromethylphenyl (PYT108) or chlorophenyl (others).

According to the results of this study, the RMSD and RMSF of the PYTs-hCa $1.2 / \mathrm{hCa}_{\mathrm{v}} 1.3$ complex were stable in the central pore region of the transmembrane helix during MD simulation, and the major fluctuations were caused by the extracellular loop. It is worth noting that ligands with low affinity could more affect the overall stability of the receptor $h \mathrm{Ca}_{\mathrm{v}} 1.3 / \mathrm{Ca}_{\mathrm{v}} 1.2$. The binding free energy calculation and conformation analysis showed that $\mathrm{hCa}_{\mathrm{v}} 1.3-\mathrm{PYT} 06$ and $\mathrm{hCa} \mathrm{v}_{\mathrm{v}}$ 1.3-PYT108 had lower binding free energy than $\mathrm{hCa}_{\mathrm{v}} 1.2-\mathrm{PYT} 06$ and $\mathrm{hCa}_{\mathrm{v}} 1.2-\mathrm{PYT} 108$, which was consistent with experimental data and other simulation systems [29]. The components of binding energy suggested that the $\Delta \mathrm{E}_{\mathrm{vdW}}$ term was the main energy contribution to the binding free energy for each system. The complex systems with high affinity retained the low $\Delta \mathrm{E}_{\mathrm{vdW}}$ in general. Moreover, the residues, such as V162, L303, M481, and F484 (residues in $\mathrm{hCa}_{\mathrm{v}} 1.3$ ), in the binding site contributed most of the binding free energy based on the energy decomposition per-residue. Comparing the binding mode of $\mathrm{hCa}_{\mathrm{v}} 1.2$ and $\mathrm{hCa}_{\mathrm{v}} 1.3$, the difference was mainly attributed to the residues that formed the hydrophobic surface in the IR2 and IR3. In our study, we also found that these differences played a decisive role in the selectivity of $\mathrm{hCa}_{\mathrm{v}} 1.3 / \mathrm{Ca}_{\mathrm{v}} 1.2$ with different ligands.

As expected, the halogen-substituted aromatic ring in PYTs could contribute the most binding affinity by the formation of hydrophobic interactions. On the other side of the PYT ring, the structure of the substituent played an important role in selectivity. It seemed that cycloalkyl and norbornyl provided the higher selectivity for $\mathrm{hCa}_{\mathrm{v}} 1.3$. The strong polarity group may be not a good choice because it could move the ligand away from the hydrophobic surface, resulting in poor binding affinity and low selectivity, just like the PYT65 and PYT67. Somewhat confusingly, the PYT67 had a poor binding affinity for $\mathrm{hCa}_{\mathrm{v}} 1.2$. It seemed that the carboxyl of PYT67 formed an intramolecular hydrogen bond, which led to the reduction of the energy change itself. Besides, steric hindrance in the binding site limited the interaction of the receptor for the ligand. Therefore, matched space size and a suitable substituent group of PYTs may increase the affinity to LTCCs.

Some of the PYTs were reported as highly selective antagonists of $\mathrm{hCa}_{\mathrm{v}} 1.3$, which could decrease side-effects on the body effectively. However, studies on the mechanism of action and pharmacology of PYTs are deficient somehow. It has been reported that the inhibitory activity of the PYT06 to LTCCs was confirmed, but the selective activity against $h \mathrm{ha}_{\mathrm{v}} 1.3$ was dependent on the $\beta$-subunit [39]. Another study indicated the PYTs may be a new class of activator for LTCCs, and the PYT06 could cause a slowing of the activation and inactivation time course, which showed that the selective inhibitory activity to $\mathrm{hCa}_{\mathrm{v}} 1.3$ of PYTs was closely dependent on the experimental conditions [40]. Therefore, further studies of PYTs and other $\mathrm{hCa}_{\mathrm{v}} 1.3$ selective inhibitors need to be performed. We expect that our study could reveal the binding mode of the $\mathrm{hCa}_{\mathrm{v}} 1.2$ and $\mathrm{hCa}_{\mathrm{v}} 1.3$ with the PYTs, which will help research on related disease and drugs targeted to LTCCs in the near future.

\section{Materials and Methods}

\subsection{Homology Modeling}

Homology modeling was applied to build the theoretical models of the $\alpha 1$-subunits on L-type calcium Channels $\mathrm{hCa}_{\mathrm{v}} 1.2$ and $\mathrm{hCa}_{\mathrm{v}} 1.3$. The amino acid sequences of the $\alpha 1$-subunits on $\mathrm{hCa}_{\mathrm{v}} 1.2$ (access number: Q13936) and $\mathrm{hCa}_{\mathrm{v}} 1.3$ (access number: Q01668) were originated from the UniProt database (www.uniprot.org). Sequence alignments of $\mathrm{hCa}_{\mathrm{v}} 1.2$ and $\mathrm{hCa}_{\mathrm{v}} 1.3$ with the sequence of 
$\mathrm{rCa}_{\mathrm{v}} 1.1$ were carried out by applying ClustalX 2.1 [41]. The $\mathrm{rCa}_{\mathrm{v}} 1.1$ (PDB ID: 5GJV) was selected as the best template to model the $\mathrm{hCa}_{\mathrm{v}} 1.2$ and $\mathrm{hCa}_{\mathrm{v}} 1.3 \alpha 1$-subunits. Modeller 9.9 [42] was used to generate the $3 \mathrm{D}$ models of the target sequences and the best ones were chosen according to DOPE value and Molpdf score [34]. According to previous reports, the central pore region could retain great credibility [43], and the binding site of PYTs is also located in the pore region. Therefore, the central pore region (S4-S6 composition) of $\mathrm{hCa}_{\mathrm{v}} 1.2$ and $\mathrm{hCa}_{\mathrm{v}} 1.3$ was selected for follow-up detailed analysis, and the optimized structures were submitted to SAVES v5.0 to evaluate their reasonability through ERRAT, PROCHECK, and WHATCHECK [35-38]. Among them, ERRAT generated the overall quality factor based on the quality of the protein, PROCHECK analyzed the residue-by-residue geometry and WHATCHECK analyzed the great stereochemical parameters via a comprehensive checking for the residues. Considering the real physiological environment, these structures were embedded in a palmitoyl-oleoyl-phosphatidyl-choline (POPC) lipid bilayer using the CHARMM-GUI online tool. Meanwhile, a total of 20952 TIP3P water models were introduced to solvate the system [44].

\subsection{Molecular Docking of PYTs to $h C a_{v} 1.3$ and $h C a_{v} 1.2$}

Autodock 4.2 [45] was used to predict the docking conformation for PYT at $\mathrm{hCa}_{\mathrm{v}} 1.3$ and $\mathrm{hCa}_{\mathrm{v}} 1.2$. The grid box was defined as a cubic binding pocket with 40 points for every side in the grid spacing of $0.375 \AA$. Two hundred binding poses were calculated through the genetic algorithm with $2.5 \times 10^{7}$ maximum number of evals and 150 population size, and the default parameters were used for other options. The binding pose of the protein-ligand complexes with the best binding mode and binding free energy was selected by clustering analysis as an initial structure for further molecular dynamics simulations.

\subsection{Molecular Dynamics Simulations}

The AMBER 16 package [46] was used to carry out molecular dynamics (MD) simulations with AMBER-ff14SB force field [47] for the selected complexes, meanwhile, the general AMBER force field (GAFF) [48] and the AMBER Lipid14 force field [49] were employed for the ligands and the POPC lipid bilayer, respectively. The receptor-ligand complex systems with membranes and water molecules were appended to a cubie cell with periodic boundary conditions, while counterions (Cl-) were added to maintain the electrical neutrality of the overall system. The particle-mesh Ewald (PME) algorithm [50] was utilized for energy minimization and molecular dynamics (MD) to calculate the long-range electrostatic interactions with a cutoff value of $12 \AA$ in the whole simulation process. The SHAKE algorithm was applied to constrain all the covalent bonds with hydrogens [51] and Langevin dynamics [52] with a collision frequency $\gamma$ of 1.0 used to control the change of temperature during MD simulation. Before the MD simulation began, energy minimization was performed in six cycles with a restraining force from 100.0 to $0 \mathrm{kcal} /\left(\mathrm{mol} \cdot \AA^{2}\right)$. In each cycle, 2500 steps conjugated gradient minimization and 2500 steps steepest-descent minimization were successively carried out to remove unnatural contact in the system. Then, the whole systems were heated to $310.0 \mathrm{~K}$ gradually with solutes restrained using a harmonic potential in the NVT ensemble. 400 ps of NTP simulations were subsequently performed for equilibrations via two steps $[53,54]$. A decreasing restraining force was applied to solutes gradually in the first step and the second step was carried out without any restraining force. Further, the production MD simulations of $100 \mathrm{~ns}$ were run at $1.0 \mathrm{~atm}$ and 310.0 $\mathrm{K}$ with $2.0 \mathrm{fs}$ time step. All complex systems were processed under the same conditions. The root mean square deviation (RMSD) of backbone atoms and the root mean square fluctuation (RMSF) of residue were calculated by the trajectory analysis tool CPPTRAJ [55] to manifest the stability of complex systems. All the calculations were submitted with the trajectory of a stable period.

\subsection{Binding Energy Calculations and Decomposition by MM/GBSA}

The molecular mechanics/generalized Born surface area (MM/GBSA) method was applied in analyzing the molecular interaction between ligand and receptor [56]. For the MM/GBSA, the $\Delta$ Gbind 
$\left(\mathrm{G}_{\text {Complex }}-\mathrm{G}_{\text {Receptor }}-\mathrm{G}_{\text {Ligand }}\right)$ were the energy differences, which were broken up into four basic objects, obtaining the van der Waals $\left(\mathrm{E}_{\mathrm{vdW}}\right)$, the electrostatic $\left(\mathrm{E}_{\mathrm{EL}}\right)$ interactions, the polar $\left(\mathrm{E}_{\mathrm{GB}}\right)$ and nonpolar (E $\left.\mathrm{E}_{\mathrm{SURF}}\right)$ contributions. The van der Waals and the electrostatic interactions are the standard MM energy terms, and the polar term is obtained generally by using the generalized Born (GB) model, while the nonpolar is typically modeled with a term proportional to the solvent accessible surface area (SASA) [57]. Here, the python script MMPBSA.py in AMBER 16 was used in calculating the binding free energy and the per-residue energy decomposition for the $\mathrm{hCa} \mathrm{a}_{\mathrm{v}} 1.3$ and $\mathrm{hCa} \mathrm{a}_{\mathrm{v}} 1.2$ against the PYTs. A total of 1000 snapshots were extracted from the last $40 \mathrm{~ns}$ trajectory from the production simulation to calculate the MM/GBSA free energy. To exhibit the binding conformation between receptor and ligand, the best representative conformation of each complex was selected using a clustering algorithm [58]. Per-residue energy decomposition was also performed to evaluate the energy contribution of each residue in the systems. All the other parameters were kept as default values. VMD 1.9.2 [59], Pymol 1.8 [60] packages and Discovery Studio Client [61] were used to display an analysis of the MD trajectories and the binding conformations.

\section{Conclusions}

In this study, six PYTs were selected to study the selectivity for $\mathrm{hCa}_{\mathrm{v}} 1.3$ and $\mathrm{hCa}_{\mathrm{v}} 1.2$ through computational dynamic simulations. The results indicate that the hydrophobic surface formed by the residues located in IR2 and IR3 play an important role between PYTs and $\mathrm{Ca}_{\mathrm{v}} 1.3 / \mathrm{Ca}_{\mathrm{v}} 1.2$. V162, L303, M481 and F484 residues (located in $\mathrm{hCa}_{\mathrm{v}} 1.3$ ) provided most of the energy contribution by the formation of hydrophobic interactions. The substituent of PYTs also affected the binding free energy. A polar group, generally, was not favorable. Suitable cycloalkyl and norbornyl groups could increase the selectivity to $\mathrm{Ca}_{\mathrm{v}} 1.3$. Moreover, a halogen-substituted aromatic ring helped PYTs to bind $\mathrm{hCa}_{\mathrm{v}} 1.3 / \mathrm{hCa}_{\mathrm{v}} 1.2$. There are still some uncertain issues, such as the energy abnormality of PYT67, which need to be solved, so we will refine and improve the final results in a further study.

Supplementary Materials: The following are available online, Figure S1: The sequence alignments of hCa 1.3 and $\mathrm{hCa}_{\mathrm{v}} 1.2$ with $\mathrm{rCa}_{\mathrm{v}} 1.1$, Figure S2: The structure of homologous models for $\mathrm{hCa}_{\mathrm{v}} 1.3$ and $\mathrm{hCa}_{\mathrm{v}} 1.2$, Figure S3: The Ramachandran plot of the models of $\mathrm{hCa}_{\mathrm{v}} 1.3$ and $h \mathrm{ha}_{\mathrm{v}} 1.2$, Figure S4: The homology models of $h \mathrm{ha}_{\mathrm{v}} 1.3$ and $\mathrm{hCa}_{\mathrm{v}} 1.2$ with lipid bilayer membranes and TIP3P water models, Table S1: The information of PYTs in the group A and group $B$ for $h \mathrm{ha}_{\mathrm{v}} 1.2$ and $\mathrm{hCa}_{\mathrm{v}} 1.3$, Table S2: Evaluation results of models of $\mathrm{hCa}_{\mathrm{v}} 1.3$ and $\mathrm{hCa}_{\mathrm{v}} 1.2$, Table S3: The residues in major interactional regions of $\mathrm{hCa}_{\mathrm{v}} 1.3$ and $\mathrm{hCa}$ 1.2 complexes of group A, Table S4: The residues in major interactional regions of $\mathrm{hCa}_{\mathrm{v}} 1.3$ and $\mathrm{hCa}_{\mathrm{v}} 1.2$ complexes of group $\mathrm{B}$.

Author Contributions: Conceptualization, Q.Y., Z.Z. and Y.S.; methodology, Q.Y., F.Z. and Y.S.; software, Q.Y. and Z.Z.; validation, Q.Y. and Z.Z.; formal analysis, W.Z. and Y.D.; investigation, W.Z. and Y.D.; resources, Y.S. and J.Z.; data curation, Q.Y.; writing-original draft preparation, Q.Y.; writing-review and editing, Q.Y., F.Z. and Y.S.; visualization, Q.Y. and Z.Z.; supervision, Y.S. and J.Z.; project administration, Y.S.; funding acquisition, Y.S. and J.Z. All authors have read and agreed to the published version of the manuscript.

Funding: This research was funded by the National Natural Science Foundation of China $(81102365,81973227)$, and the research foundation of education bureau of Liaoning province (No: 2019LZD02).

Conflicts of Interest: The authors declare no conflict of interest.

\section{References}

1. Triggle, D.J. L-type calcium channels. Curr. Pharm. Des. 2006, 12, 443-457. [CrossRef]

2. Zamponi, G.W.; Striessnig, J.; Koschak, A.; Dolphin, A.C. The Physiology, Pathology, and Pharmacology of Voltage-Gated Calcium Channels and Their Future Therapeutic Potential. Pharmacol. Rev. 2015, 67, 821-870. [CrossRef]

3. Moosmang, S.; Lenhardt, P.; Haider, N.; Hofmann, F.; Wegener, J.W. Mouse models to study L-type calcium channel function. Pharmacol. Ther. 2005, 106, 347-355. [CrossRef] [PubMed]

4. Lipscombe, D.; Helton, T.D.; Xu, W. L-Type Calcium Channels: The Low Down. J. Neurophysiol. 2004, 92, 2633-2641. [CrossRef] [PubMed] 
5. Catterall, W.A.; Perez-Reyes, E.; Snutch, T.P.; Striessnig, J. International Union of Pharmacology. XLVIII. Nomenclature and Structure-Function Relationships of Voltage-Gated Calcium Channels. Pharmacol. Rev. 2005, 57, 411-425. [CrossRef]

6. Hofmann, F.; Flockerzi, V.; Kahl, S.; Wegener, J.W. L-Type CaV1.2 Calcium Channels: From In Vitro Findings to In Vivo Function. Physiol. Rev. 2014, 94, 303-326. [CrossRef] [PubMed]

7. Singer, D.; Biel, M.; Lotan, I.; Flockerzi, V.; Hofmann, F.; Dascal, N. The roles of the subunits in the function of the calcium channel. Science 1991, 253, 1553-1557. [CrossRef] [PubMed]

8. Szappanos, H.C.; Viola, H.; Hool, L.C. L-type calcium channel: Clarifying the "oxygen sensing hypothesis". Int. J. Biochem. Cell Biol. 2017, 86, 32-36. [CrossRef] [PubMed]

9. Zuccotti, A.; Clementi, S.; Reinbothe, T.; Torrente, A.; Vandael, D.H.; Pirone, A. Structural and functional differences between L-type calcium channels: Crucial issues for future selective targeting. Trends Pharmacol. Sci. 2011, 32, 366-375. [CrossRef]

10. Kang, S.; Cooper, G.; Dunne, S.F.; Luan, C.-H.; Surmeier, D.J.; Silverman, R.B. Antagonism of L-type $\mathrm{Ca}^{2+}$ channels CaV1.3 and CaV1.2 by 1,4-dihydropyrimidines and $4 \mathrm{H}$-pyrans as dihydropyridine mimics. Bioorg. Med. Chem. 2013, 21, 4365-4373. [CrossRef]

11. Liao, P.; Soong, T.W. CaV1.2 channelopathies: From arrhythmias to autism, bipolar disorder, and immunodeficiency. Pflïg. Arch. Eur. J. Physiol. 2010, 460, 353-359. [CrossRef] [PubMed]

12. Baig, S.M.; Koschak, A.; Lieb, A.; Gebhart, M.; Dafinger, C.; Nürnberg, G.; Ali, A.; Ahmad, I.; Sinnegger-Brauns, M.J.; Brandt, N.; et al. Loss of Cav1.3 (CACNA1D) function in a human channelopathy with bradycardia and congenital deafness. Nat. Neurosci. 2011, 14, 77-84. [CrossRef] [PubMed]

13. Locatelli, A.; Cosconati, S.; Micucci, M.; Leoni, A.; Marinelli, L.; Bedini, A.; Ioan, P.; Spampinato, S.M.; Novellino, E.; Chiarini, A.; et al. Ligand Based Approach to L-Type Calcium Channel by Imidazo[2,1-b]thiazole-1,4-Dihydropyridines: From Heart Activity to Brain Affinity. J. Med. Chem. 2013, 56, 3866-3877. [CrossRef] [PubMed]

14. Kaczorowski, G.J.; McManus, O.B.; Priest, B.T.; Garcia, M.L. Ion Channels as Drug Targets: The Next GPCRs. J. Gen. Physiol. 2008, 131, 399-405. [CrossRef]

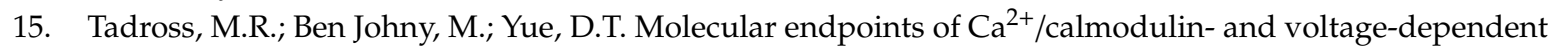
inactivation of Cav1.3 channels. J. Gen. Physiol. 2010, 135, 197-215. [CrossRef]

16. Waszkielewicz, A.; Gunia, A.; Szkaradek, N.; Sloczynska, K.; Krupinska, S.; Marona, H. Ion Channels as Drug Targets in Central Nervous System Disorders. Curr. Med. Chem. 2013, 20, 1241-1285. [CrossRef]

17. Chan, C.S.; Guzman, J.N.; Ilijic, E.; Mercer, J.N.; Rick, C.; Tkatch, T.; Meredith, G.E.; Surmeier, D.J. 'Rejuvenation' protects neurons in mouse models of Parkinson's disease. Nature 2007, 447, 1081-1086. [CrossRef]

18. McDonough, S.I. Calcium Channel Pharmacology; Springer Science \& Business Media: New York, NY, USA, 2011.

19. Adachi-Akahane, S.; Nagao, T. $\mathrm{Ca}^{2+}$ channel antagonists and agonists. In Pharmacology of Ionic Channel Function: Activators and Inhibitors; Springer: Berlin, Germany, 2000; pp. 119-154.

20. Striessnig, J.; Grabner, M.; Mitterdorfer, J.; Hering, S.; Sinnegger, M.; Glossmann, H. Structural basis of drug binding to $\mathrm{L} \mathrm{Ca}^{2+}$ channels. Trends Pharmacol. Sci. 1998, 19, 108-115. [CrossRef]

21. Striessnig, J.; Ortner, N.J.; Pinggera, A. Pharmacology of L-type Calcium Channels: Novel Drugs for Old Targets? Curr. Mol. Pharmacol. 2015, 8, 110-122. [CrossRef]

22. Fermini, B.; Ramirez, D.S.; Sun, S.; Bassyouni, A.; Hemkens, M.; Wisialowski, T.; Jenkinson, S. L-type calcium channel antagonism-Translation from in vitro to in vivo. J. Pharmacol. Toxicol. Methods 2017, 84, 86-92. [CrossRef]

23. Tikhonov, D.B.; Zhorov, B.S. Structural Model for Dihydropyridine Binding to L-type Calcium Channels. J. Biol. Chem. 2009, 284, 19006-19017. [CrossRef] [PubMed]

24. Sinnegger-Brauns, M.J.; Huber, I.G.; Koschak, A.; Wild, C.; Obermair, G.J.; Einzinger, U.; Hoda, J.-C.; Sartori, S.B.; Striessnig, J.; Striessnig, J. Expression and 1,4-Dihydropyridine-Binding Properties of Brain L-Type Calcium Channel Isoforms. Mol. Pharmacol. 2009, 75, 407-414. [CrossRef] [PubMed]

25. Koschak, A.; Reimer, D.; Huber, I.G.; Grabner, M.; Glossmann, H.; Engel, J.; Striessnig, J. $\alpha 1 D$ (Cav1.3) Subunits Can Form L-type $\mathrm{Ca}^{2+}$ Channels Activating at Negative Voltages. J. Biol. Chem. 2001, 276, 22100-22106. [CrossRef] [PubMed]

26. Tenti, G.; Egea, J.; Fernández, J.C.; Padín-Nogueira, F.; Sridharan, V.; Ramos, M.T.; Menéndez, J.C.; Villarroya, M.; León, R. Identification of 4,6-diaryl-1,4-dihydropyridines as a new class of neuroprotective agents. MedChemComm 2013, 4, 590-594. [CrossRef] 
27. Tarabová, B.; Nováková, M.; Lacinova, L. Haloperidol moderately inhibits cardiovascular L-type calcium current. Gen. Physiol. Biophys. 2009, 28, 249-259. [CrossRef]

28. Rodrigues, T.; Sieglitz, F.; Somovilla, V.J.; Cal, P.M.S.D.; Galione, A.; Corzana, F.; Bernardes, G.J.L. Unveiling (-)-Englerin A as a Modulator of L-Type Calcium Channels. Angew. Chem. Int. Ed. 2016, 55, 11077-11081. [CrossRef]

29. Kang, S.; Cooper, G.; Dunne, S.F.; Dusel, B.; Luan, C.H.; Surmeier, D.J.; Silverman, R.B. CaV1.3-selective L-type calcium channel antagonists as potential new therapeutics for Parkinson's disease. Nat. Commun. 2012, 3, 1146. [CrossRef]

30. Kang, S.; Cooper, G.; Dunne, S.F.; Luan, C.-H.; Surmeier, D.J.; Silverman, R.B. Structure-Activity Relationship of $\mathrm{N}, \mathrm{N}^{\prime}$-Disubstituted Pyrimidinetriones as CaV1.3 Calcium Channel-Selective Antagonists for Parkinson's Disease. J. Med. Chem. 2013, 56, 4786-4797. [CrossRef]

31. Xia, G.; Benmohamed, R.; Kim, J.; Arvanites, A.C.; Morimoto, R.I.; Ferrante, R.J.; Kirsch, D.R.; Silverman, R.B. Pyrimidine-2,4,6-trione Derivatives and Their Inhibition of Mutant SOD1-Dependent Protein Aggregation. Toward a Treatment for Amyotrophic Lateral Sclerosis. J. Med. Chem. 2011, 54, 2409-2421. [CrossRef]

32. Tang, L.; El-Din, T.M.G.; Payandeh, J.; Martinez, G.Q.; Heard, T.M.; Scheuer, T.; Zheng, N.; Catterall, W.A. Structural basis for $\mathrm{Ca}^{2+}$ selectivity of a voltage-gated calcium channel. Nature 2014, 505, 56-61. [CrossRef]

33. Wu, J.; Yan, Z.; Li, Z.; Qian, X.; Lu, S.; Dong, M.; Zhou, Q.; Yan, N. Structure of the voltage-gated calcium channel Ca v 1.1 at $3.6 \AA$ resolution. Nature 2016, 537, 191-196. [CrossRef]

34. Shen, M.-Y.; Sali, A. Statistical potential for assessment and prediction of protein structures. Protein Sci. 2006, 15, 2507-2524. [CrossRef]

35. Colovos, C.; Yeates, T.O. Verification of protein structures: Patterns of nonbonded atomic interactions. Protein Sci. 1993, 2, 1511-1519. [CrossRef]

36. Laskowski, R.A.; MacArthur, M.W.; Moss, D.S.; Thornton, J.M. PROCHECK: A program to check the stereochemical quality of protein structures. J. Appl. Crystallogr. 1993, 26, 283-291. [CrossRef]

37. Laskowski, R.A.; Rullmann, J.A.C.; MacArthur, M.W.; Kaptein, R.; Thornton, J.M. AQUA and PROCHECK-NMR: Programs for checking the quality of protein structures solved by NMR. J. Biomol. NMR 1996, 8, 477-486. [CrossRef] [PubMed]

38. Vriend, G. WHAT IF: A molecular modeling and drug design program. J. Mol. Graph. 1990, 8, 52-56. [CrossRef]

39. Huang, H.; Ng, C.Y.; Yu, D.; Zhai, J.; Lam, Y.; Soong, T.W. Modest Ca V 1.3 42-selective inhibition by compound 8 is $\beta$-subunit dependent. Nat. Commun. 2014, 5, 1-7. [CrossRef]

40. Ortner, N.J.; Bock, G.; Vandael, D.H.; Mauersberger, R.; Draheim, H.J.; Gust, R.; Carbone, E.; Tuluc, P.; Striessnig, J. Pyrimidine-2,4,6-triones are a new class of voltage-gated L-type $\mathrm{Ca}^{2+}$ channel activators. Nat. Commun. 2014, 5, 3897. [CrossRef]

41. Larkin, M.; Blackshields, G.; Brown, N.; Chenna, R.; Mcgettigan, P.; McWilliam, H.; Valentin, F.; Wallace, I.M.; Wilm, A.; Lopez, R.; et al. Clustal W and Clustal X version 2.0. Bioinformatics 2007, 23, 2947-2948. [CrossRef]

42. Webb, B.; Sali, A. Comparative Protein Structure Modeling Using MODELLER. Curr. Protoc. Bioinform. 2016, 54, 5.6.1-5.6.37. [CrossRef]

43. Xu, L.; Li, D.; Tao, L.; Yang, Y.; Li, Y.; Hou, T. Binding mechanisms of 1,4-dihydropyridine derivatives to L-type calcium channel Cav1.2: A molecular modeling study. Mol. BioSyst. 2016, 12, 379-390. [CrossRef]

44. Wu, E.L.; Cheng, X.; Jo, S.; Rui, H.; Song, K.C.; Dávila-Contreras, E.M.; Qi, Y.; Lee, J.; Monje-Galvan, V.; Venable, R.M.; et al. CHARMM-GUIMembrane Buildertoward realistic biological membrane simulations. J. Comput. Chem. 2014, 35, 1997-2004. [CrossRef]

45. Morris, G.M.; Huey, R.; Lindstrom, W.; Sanner, M.F.; Belew, R.K.; Goodsell, D.S.; Olson, A.J. AutoDock4 and AutoDockTools4: Automated docking with selective receptor flexibility. J. Comput. Chem. 2009, 30, 2785-2791. [CrossRef] [PubMed]

46. Case, D.A.; Cheatham, T.E., III; Simmerling, C.L.; Wang, j.; Duke, R.E.; Luo, R.; Walker, R.C.; Zhang, W.; Merz, K.M.; Roberts, B.; et al. Amber 16; University of California: San Francisco, CA, USA, 2016.

47. Maier, J.A.; Martinez, C.; Kasavajhala, K.; Wickstrom, L.; Hauser, K.E.; Simmerling, C. ff14SB: Improving the Accuracy of Protein Side Chain and Backbone Parameters from ff99SB. J. Chem. Theory Comput. 2015, 11, 3696-3713. [CrossRef] [PubMed]

48. Wang, J.; Wolf, R.M.; Caldwell, J.W.; Kollman, P.A.; Case, D.A. Development and testing of a general amber force field. J. Comput. Chem. 2004, 25, 1157-1174. [CrossRef] [PubMed] 
49. Dickson, C.J.; Madej, B.D.; Skjevik, Å.A.; Betz, R.M.; Teigen, K.; Gould, I.R.; Walker, R.C. Lipid14: The Amber Lipid Force Field. J. Chem. Theory Comput. 2014, 10, 865-879. [CrossRef]

50. Darden, T.; York, D.M.; Pedersen, L. Particle mesh Ewald: AnN·log(N) method for Ewald sums in large systems. J. Chem. Phys. 1993, 98, 10089-10092. [CrossRef]

51. Ryckaert, J.-P.; Ciccotti, G.; Berendsen, H.J. Numerical integration of the cartesian equations of motion of a system with constraints: Molecular dynamics of n-alkanes. J. Comput. Phys. 1977, 23, 327-341. [CrossRef]

52. Izaguirre, J.A.; Catarello, D.P.; Wozniak, J.M.; Skeel, R.D. Langevin stabilization of molecular dynamics. J. Chem. Phys. 2001, 114, 2090-2098. [CrossRef]

53. Stella, L.; Melchionna, S. Equilibration and sampling in molecular dynamics simulations of biomolecules. J. Chem. Phys. 1998, 109, 10115-10117. [CrossRef]

54. Walton, E.B.; Vanvliet, K.J. Equilibration of experimentally determined protein structures for molecular dynamics simulation. Phys. Rev. E 2006, 74, 061901. [CrossRef] [PubMed]

55. Roe, D.R.; Cheatham, I.T.E. PTRAJ and CPPTRAJ: Software for Processing and Analysis of Molecular Dynamics Trajectory Data. J. Chem. Theory Comput. 2013, 9, 3084-3095. [CrossRef] [PubMed]

56. Hou, T.; Wang, J.; Li, Y.; Wang, W. Assessing the Performance of the MM/PBSA and MM/GBSA Methods. 1. The Accuracy of Binding Free Energy Calculations Based on Molecular Dynamics Simulations. J. Chem. Inf. Model. 2011, 51, 69-82.

57. Genheden, S.; Ryde, U. The MM/PBSA and MM/GBSA methods to estimate ligand-binding affinities. Expert Opin. Drug Discov. 2015, 10, 449-461. [CrossRef]

58. Shao, J.; Tanner, S.W.; Thompson, N.; Cheatham, T.E. Clustering Molecular Dynamics Trajectories: 1. Characterizing the Performance of Different Clustering Algorithms. J. Chem. Theory Comput. 2007, 3, 2312-2334. [CrossRef]

59. Humphrey, W.; Dalke, A.; Schulten, K. VMD: Visual molecular dynamics. J. Mol. Graph. 1996, 14, 33-38. [CrossRef]

60. DeLano, W.L. The PyMOL Molecular Graphics System, Vearsion 1.8; Schrödinger, LLC.: New York, NY, USA, 2015.

61. BioVia. Discovery Studio 2019; BioVia: San Diego, CA, USA, 2019.

Sample Availability: Not Available.

Publisher's Note: MDPI stays neutral with regard to jurisdictional claims in published maps and institutional affiliations.

(C) 2020 by the authors. Licensee MDPI, Basel, Switzerland. This article is an open access article distributed under the terms and conditions of the Creative Commons Attribution (CC BY) license (http://creativecommons.org/licenses/by/4.0/). 